\title{
OPTIMAL CONTROL IN SELECTIVE CATALYTIC REDUCTION USING LINEAR QUADRATIC REGULATOR
}

\author{
A Thesis by \\ Aishvarya Hariharan \\ Bachelor of Engineering, Anna University, 2011
}

Submitted to the Department of Electrical Engineering and Computer Science and the faculty of the Graduate School of

Wichita State University

in partial fulfillment of

the requirements for the degree of

Master of Science

May 2016 
(C) Copyright 2016 by Aishvarya Hariharan

All Rights Reserved 


\section{OPTIMAL CONTROL IN SELECTIVE CATALYTIC REDUCTION USING LINEAR QUADRATIC REGULATOR}

The following faculty members have examined the final copy of the thesis for form and content, and recommend that it be accepted in partial fulfillment of the requirement for the degree of Master of Science with major in Electrical Engineering.

John M. Watkins, Committee Chair

M. Edwin Sawan, Committee Member

Esra Buyuktahtakin, Committee Member 


\section{DEDICATION}

To my professors Dr. John Watkins, M. Edwin Sawan for his immense support, my Colleagues in Born Inc, for their understanding and encouragement to do this research and my family for their continued support 


\section{ACKNOWLEDGEMENTS}

It is my privilege and pleasure to express my profound sense of respect, gratitude to my advisor Dr. John Watkins, Dr. Edwin Sawan, Professor Emeritus, Wichita State University for his valuable inputs, guidance and constant motivation throughout this research and even before that. I wish to express my deep gratitude to my company CEO Dr. Sidney Born, my vice president Mr. Vijay K Rachakonda, my colleagues Ms. Glory Srivastava and Mr. Dhananjay Dhane for their support and their constructive criticism which led the successful completion of this thesis. I would like to thank all the staff, friends and family for their good wishes and their motivation which led the successful completion of the thesis. Finally, I thank all those who directly and indirectly helped me in this regard. 


\section{TABLE OF CONTENTS}

Chapter

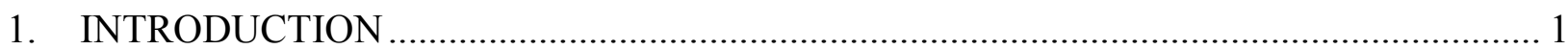

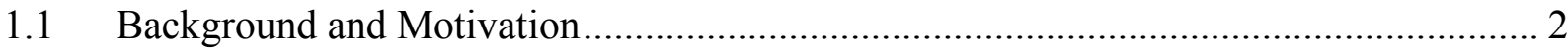

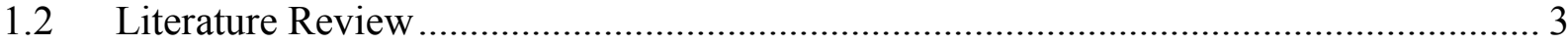

1.3 Chemical Reaction inside Selective Catalytic Reactor ............................................ 7

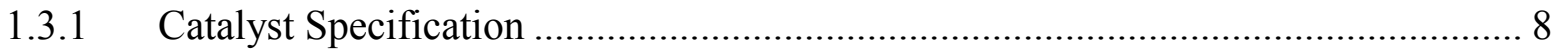

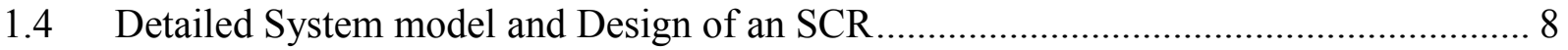

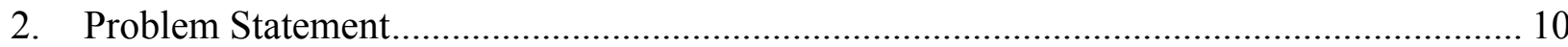

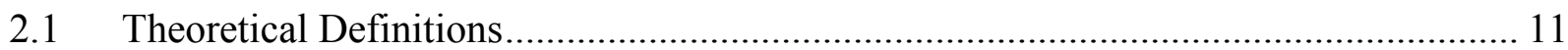

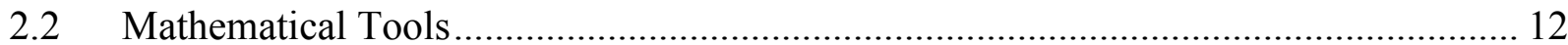

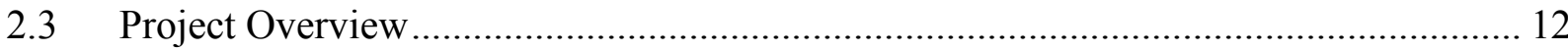

3. NOx Controller as PID Controller........................................................................... 13

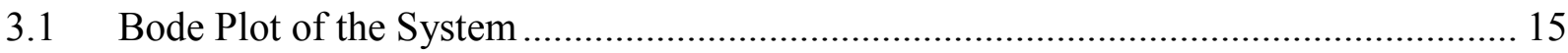

3.2 Computing the Performance of PID Controller [NOx Controller] ............................. 17

3.2.1 Generating State Feedback Controller ......................................................... 20

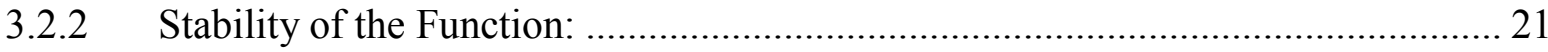

3.3 Computation of Nominal Cost Function in NOx controller..................................... 23

4. Implementing LQR Technique in NOx Controller................................................. 26

4.1 Computing Minimum Cost in NOx Controller ....................................................... 27

4.2 Comparison of PID and LQR Performance in NOx Controller ................................ 29

5. Ammonia Controller as PID Controller...................................................................... 30

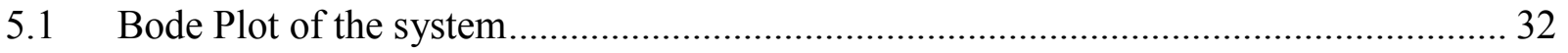

5.2 Computing the Performance of PID Controller [NH3 Controller] ............................. 33

5.3 Generating State Feedback Controller ................................................................ 35

5.4 Computation of Nominal Cost function of Ammonia Controller ............................... 39 


\section{TABLE OF CONTENTS (continued)}

Chapter

6. Implementing LQR Technique in NH3 Controller..................................................... 41

6.1 Computing Minimum Cost in NH3 Controller ...................................................... 42

6.2 Comparison of PID and LQR Performance in Ammonia Controller.......................... 43

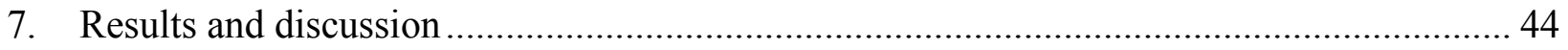

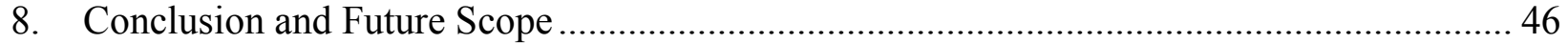

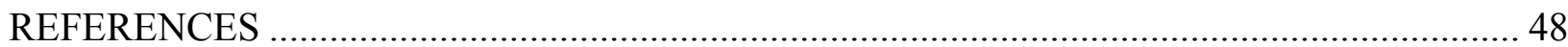

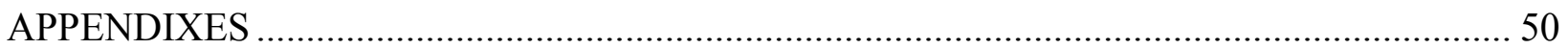

A. MATLAB code for Chapter 4 and 5 in NOx Controller ................................................. 51

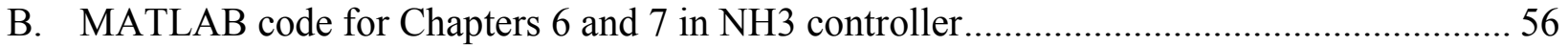




\section{LIST OF TABLES}

Table

Page

1. Tabulation of Post combustion technologies...........................................

2. Real time Values of Selective Catalytic Reactor process for reduction and

Control of NOx............................................................... 15 


\section{LIST OF FIGURES}

Figure

Page

1. Experimental Setup of NOx Reduction technique in direct fired heaters ...............5

2. Selective Catalytic Reactor Model ...........................................6

3. Detailed control system model if Selective Catalytic Reactor having Cascade Controller .........................................................9

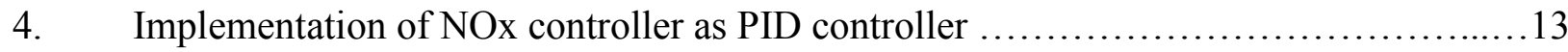

5. Feedback model of NOx controller as PID controller ............................14

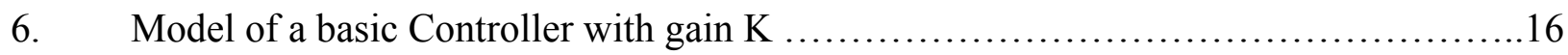

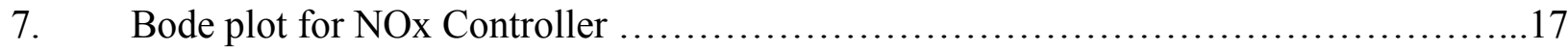

8. Performance graph of NOx implementing PID Controller with and without ..............19 PID Controller

9. PID performance Vs Linear Quadratic Regulator performance of a NOx Controller.......29

10. Figure showing how NOx controller as a PID controller .......................... 31

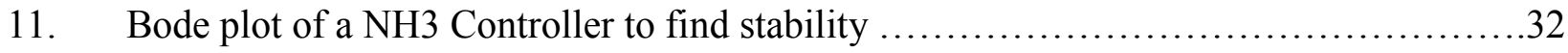

12. Performance graph of a NH3 controller with and without unity feedback ..............35

13. Performance Comparison of NH3 controller implementing PID Vs LQR ................44

14. Comparing results of PID Vs LQR techniques implemented in NOx Controller ........45

15. Comparing results of PID Vs LQR techniques implemented in NOx Controller...........45 


\begin{abstract}
In current scenario, it is significant to have harmful emissions under control and supervision by deploying control technology is indispensable. In the thermal power plants, diesel engine industries hazardous gases are being emitted and Nitric Oxide gases (represented by NOx) are one among them. Thus, (EPA) Environmental Protection Agency has set standards where the industry has to pertain to it in order to minimize the level of NOx to a certain level. Selective Catalytic Reduction (SCR) means converting nitrogen oxides [NOx] with the aid of a catalyst into nitrogen and water using a reducing agent ammonia (NH3) in this example. In the existing system, the two classical Proportional Integral Derivative controllers (cascade controller) is employed to reduce the NOx value by predicting the set point of ammonia. In this process, we get higher cost, increased peak overshoot and more settling time, which caused time delay affecting the process to a certain extent. In the proposed system, we are incorporating Linear Quadratic Regulator in place of two PID controllers, where we optimize the system to get a constant feedback which overcomes the existing disadvantages of the existing system. The LQR technique minimizes the energy of the system by giving minimum cost which is lesser than that of nominal cost of the system. This also gives low cost, faster setting time and less peak overshoot when compared to PID controller.
\end{abstract}




\section{INTRODUCTION}

Nitrogen Oxide (NOx) emissions contribute to environmental problems which include photochemical smog, acid rain, and elevated particulate elements. The increased amount of NOx causes Acid Rain when it reaches atmosphere which in turn be responsible for Ozone layer depletion also. Nitric oxides NO and NO2, collectively called NOx are less obvious products of combustion of hydrocarbon fuels, which participates in a chain reaction that removes ozone from the stratosphere ${ }^{[2]}$. The result is increased ultraviolet (UV) radiation reaching the surface of the ground. Consequently, minimization of NOx emissions is one of the most important topics in combustion wherein all the plant operations Selective Catalytic Reduction technique is being incorporated to reduce the amount of Nitric Oxides (NOx) according to the EPA standards ${ }^{[9]}$. SCR is a proven technology first patented by a company in the United States in the year 1959, it finds its largest application in coal-fired power plants. The Environmental Protection Agency estimates that national emissions of nitric acids are 18.2 million tons which can cause adverse human health effects. Our main aim is to reduce the Percentage of NOx in the flue gas.

Reduction of NOx can be done using selective catalytic reduction (SCR) [Catalyst is important for the process to take place] or selective non-catalytic reduction (SNCR) [No need of

catalyst]. These two techniques are deployed in industries based on the requirement ${ }^{[10]}$. The capital cost of selective non-catalytic reduction Technology (SNCR) is lesser than that of SCR technique which removes up to $80 \%$ of NOx content. SCR cost is higher than that of SNCR but it can achieve NOx reduction up to $95 \%$ with the help of a catalyst which speeds up the reaction. SCR is declared as the most efficient technology since provides the best alteration rate. Selective catalytic reducers (SCR) are used to capture NOx in flue gases from manufacturing plants, industrial process, and power 
generation systems. Light and heavy duty diesel engines which used in either marine or commercial applications use SCR technology to reduce NOx and meet current emission standards.

In Chapter 1, we know about the overview and background study of NOx reduction and discuss the motivation behind selective catalytic reactor where we discussed the EPA standards to maintain NOx under a certain level. In Chapter2, will discuss entire experimental setup for the NOx reduction process and also detailed system model for SCR Technique. In Chapter 3, we will discuss the problem statement for the proposed method and also related definitions.

\subsection{Background and Motivation}

In every power plant, combustion process takes place which is nothing but a rapid chemical of a fuel combining with oxygen to give heat and light. Criteria for the NOx control has been established as part of the Clean Air Act in $1977^{[11]}$. The NOx emissions are important to meet lowest attainable emission rates (LAER) standard based on the capabilities of emissions control technology which are referred to us as NSPS (New Source Performance Standards). The program called Clean Air Act Amendment (CAAA) includes annual declines in the emissions levels of NOx incorporating two-phase approach for NOx reduction that needs to comply with federal ozone standards ${ }^{[4]}$.

Most of the furnaces use post-combustion technologies to control NOx or aqueous ammonia solution. The below table shows the types of post combustion technologies separately below.

Table 1-Summary of Post Combustion Technologies

\begin{tabular}{|l|l|c|c|c|}
\hline \multirow{2}{*}{$\begin{array}{c}\text { Control } \\
\text { Technology }\end{array}$} & \multicolumn{1}{|c|}{ Application } & \multirow{2}{*}{$\begin{array}{c}\text { NOx Reduction } \\
(\%)\end{array}$} & \multicolumn{2}{c|}{ Capital Cost } \\
\cline { 4 - 5 } & & & (S/Ton) & (S/kW) \\
\hline SNCR & Boilers/Process Heaters & $40-60$ & $500-1000$ & $10-20$ \\
\hline SCR & Boilers/Process Heaters & $80-90$ & $1000-10,000$ & $20-200$ \\
\hline
\end{tabular}


Selective catalytic reduction technology is based on a selective reaction between the reagent and NOx occurs on the surface of a catalyst. Low temperature, High temperature, and conventional catalyst are three type of catalytic design occurring during post-combustion. In this project, we consider low-temperature catalyst design, located between air preheater and stack. Implementation of combustion control procedures with the Selective Catalytic Reactor can reduce the size and operating costs for the SCR significantly up to $95 \%$.

\section{$1.2 \quad$ Literature Review}

NOx reduction technique in Selective Catalytic Reactor is the most widely used technique and it is been implemented using various techniques in the past. There are many applications of the Selective Catalytic Reduction Technique that have been using conventional methods such as proportional and integral Controllers which has large dead times making it less effective ${ }^{[1]}$. The realtime optimization of the SCR model technique and methods ${ }^{[2]}$ involving Fuzzy Logic ${ }^{[3]}{ }^{[4]}$ is more complex. Selective Catalytic Method has been implemented using a technique using Generalized Predictive Controller for NOx control and Feedforward controller for Ammonia controller ${ }^{[5]}$. Since these controllers have been designed independently the output response has been affected due to disturbance changes. By using GPC and LQR in the cascade and by implementing multi-rate time sampling system is facilitating the system to withstand large computational load ${ }^{[1]}$. This paper also discussed about the output response of GPC+PI controller together and the output response of GPC+LQR Controller together and we can clearly conclude that the GPC and LQR controller combinations works much better by reducing the fluctuations of Ammonia controller which in turn ensure the proper flow of NOx. The paper also discussed about the advantages of using GPC and LQR controller together and the evaluations shows improvement in feedback performance, prevention of undershoot at disturbance change, reduction in error and better operating range ${ }^{[1]}$. 
The Technique related to Selective catalytic Reduction technique using Linear Quadratic Regulator is previously applied to non-linear systems such as Thermal power plants and turbines. In this technique, they have considered a non-linear system having a time delay used a multi-variable sampling system in order to achieve a faster response in an Ammonia Injection system ${ }^{[6]}$. In prior to this techniques, due to unreacted NOx, the Multivariable Generalized Predictive Controller has been used with ExpARX model ${ }^{[6]}$ where the cascade control having NOx controller uses GPC and Ammonia controller uses Linear Quadratic Regulator. The Digital implementation scheme is also developed that has a compensator deployed to reduce the effect of high-frequency noise and for the disturbance rejection of the system ${ }^{[6]}$.

The model based control of Selective Catalytic Reduction has been used where the feedforward controller was replaced by a model-based feedforward control. It focuses on the analysis of nitric oxide formation as a function of combustion parameters ${ }^{[8]}$ and the essential steps of this process is reduction steps of NOx and prevention of Ammonia slip (caused by excess of Ammonia in the process). This method has a separate model for the flue gas flow rate for NO concentration, which overcomes the methods that use models without former knowledge of the process ${ }^{[8]}$.

\section{Experimental Setup Explaining overall process NOx Reduction in Heaters}

NOx reduction technique, in this case, has been applied to direct fired heaters focusing on three mechanisms namely Thermal NOx, Prompt NOx and Fuel NOx. This reduction of NOx Reduce gas residence time and peak temperatures of the flame zone. In this paper, we focus on fuel NOx, where nitrogen atoms are bound in the fuel chemically ${ }^{[1]}$. Nitrogen atoms are more active if the fuel 
is a liquid than a gas. Ammonia and amines in the fuel contribute to fuel NOx formation.

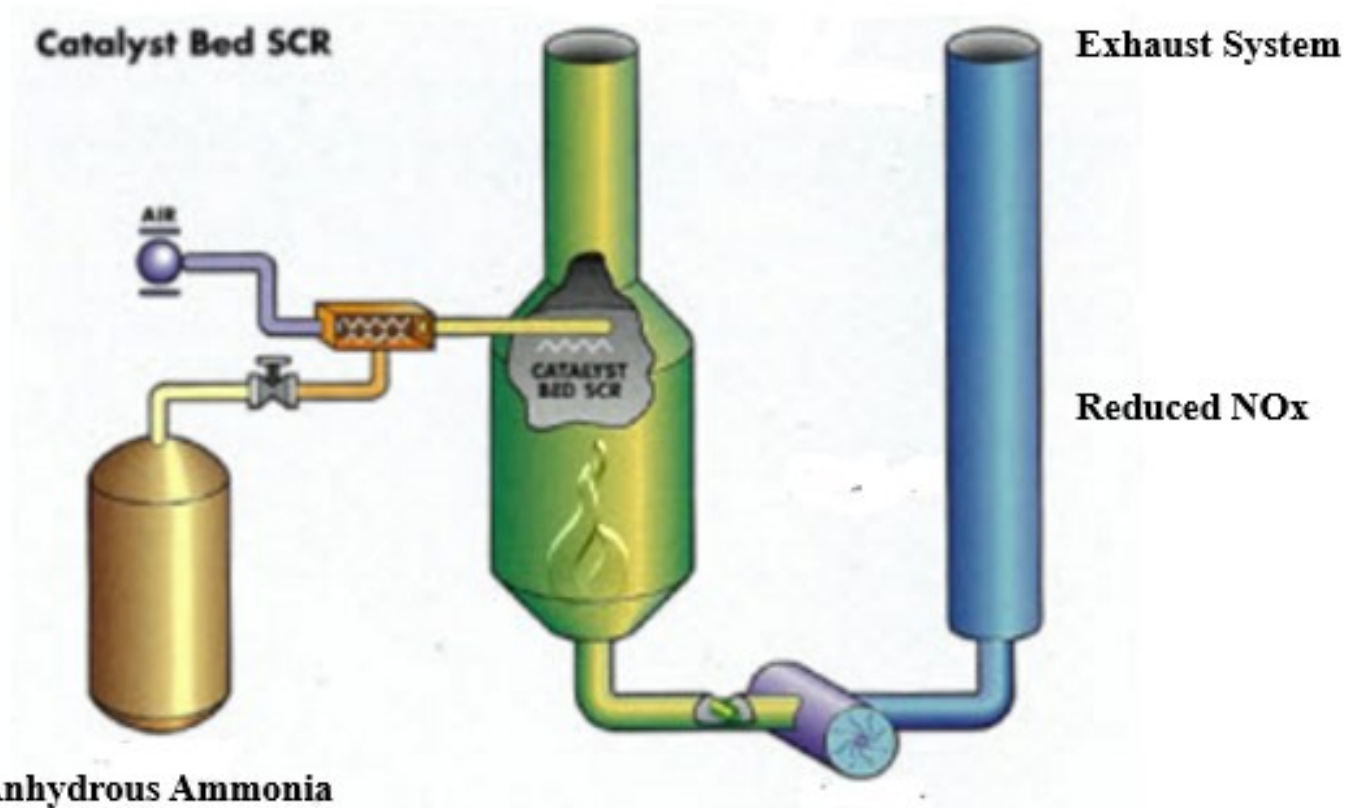

Anhydrous Ammonia

Source: http://www.borninc.com/products/selective-catalytic-reducers

Figure 1 : Experimental Setup of NOx Reduction Technique in Direct Fired Heaters

Controlling NOx emissions occurs in two approaches in combustion gas by modifying the combustion process in an attempt to prevent the NOx formation. Then we treat the combustion gas after the flame (Post-combustion) to convert NO2 into N2. The above figure shows the overall process in the direct fired heater where Selective Catalytic Reactor is employed to reduce NOx percentage. The system utilizes aqueous ammonia, which is mixed with heated high-temperature dilution air in a vaporizer tower. Upon being vaporized, the mixture is directed to the distribution header where it is injected directly into the exhaust gas upstream of the SCR catalyst bed.

As the treated exhaust gas flows through the catalyst bed, a chemical reaction occurs and reduces the NOx emissions. 


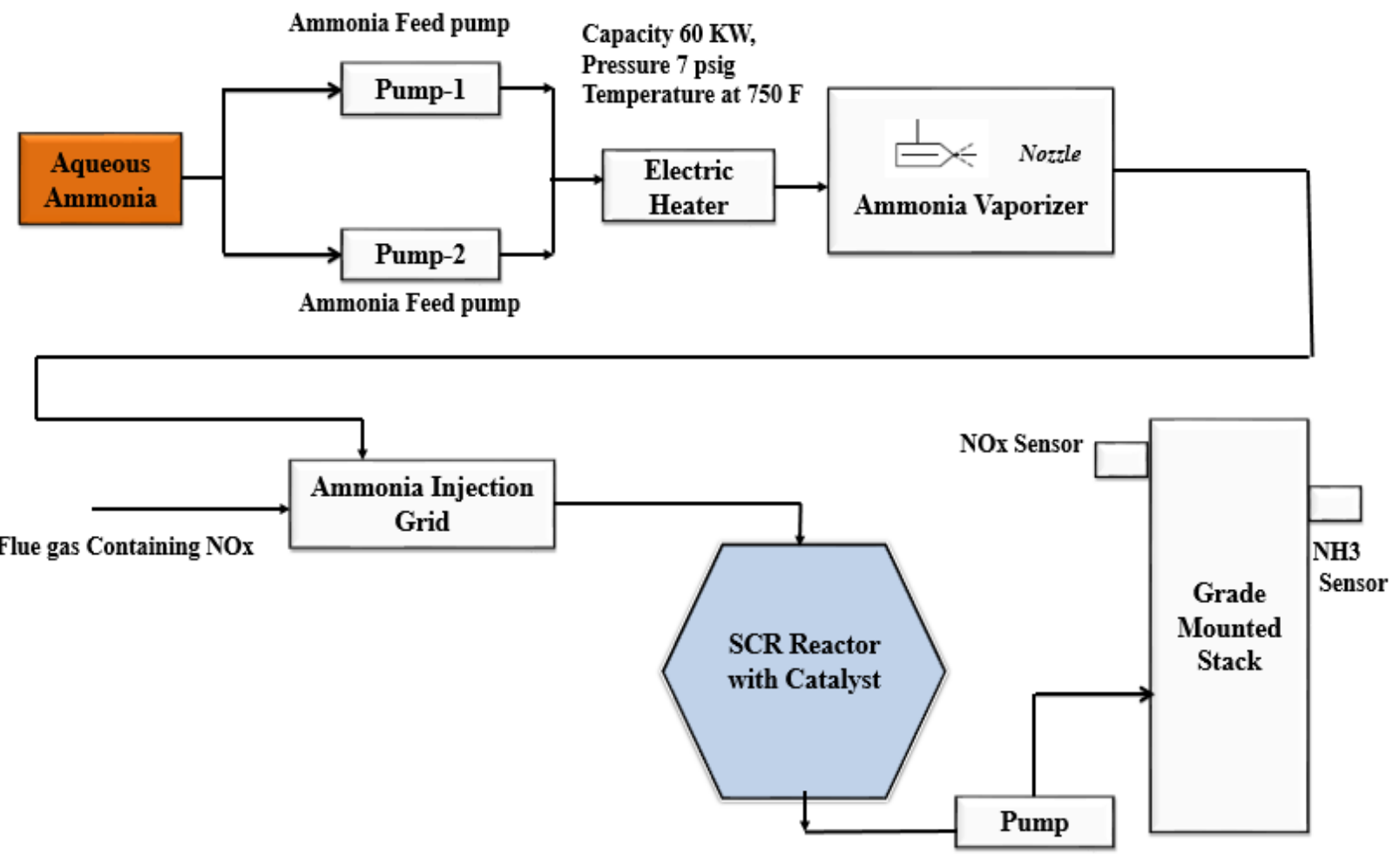

Figure 2 : Selective Catalytic Reactor Model

The above figure shows the overall process of Selective Catalytic Reactor in which our main goal is to reduce the Amount of NOx in the flue gas that contain Nitric Oxides. In SCR, we have to make NOx react with Ammonia which gives Nitrogen and water. So, 19\% of Aqueous Ammonia solution that is prepared is been fed into the Ammonia feed pump.

The Ammonia is fed in to an Electric heater at a temperature of $750 \mathrm{~F}$ where the ammonia should be vaporized in order to make it react with NOx. Therefore, the Ammonia is vaporized inside an Ammonia Vaporizer containing a Nozzle. This vaporized ammonia is then sent to an Ammonia Injection grid connected to the SCR Reactor bed which contains the catalyst. Since SCR process takes place only in the presence of catalyst, catalyst is very important for this process to take place. After the reaction takes place inside the SCR reaction chamber, it is been sent to a mounted stack where 
we measure the concentration of NOx and Ammonia in the process. The NOx is measured by a CEMS (Continuous Emission Monitoring sensor) and Ammonia is measured using Ammonia Sensor.

\subsection{Chemical Reaction inside Selective Catalytic Reactor}

NOx is a hazardous gas which is been produced in heaters and is present in significant amount in Flue gases. Our main aim is to reduce the Percentage of NOx in the flue gas. Reduction of NOx can be done using

$>\quad$ Selective Catalytic Reduction (SCR) [Catalyst is important for the process to take place]

$>\quad$ Selective Non-Catalytic Reduction (SNCR) [No need of catalyst]

The Selective Catalytic Reduction (SCR) System described in this manual is designed to reduce oxides of Nitrogen (NOx) from combustion turbine exhaust gases. As the exhaust gas mixes with ammonia and flows over a catalyst bed, the NOx is reduced to Nitrogen (N2) gas and water (H20) vapor.

\section{SCR Chemistry}

The most significant reactions that reduce NO and NO2 with $\mathrm{NH} 3$ are the following:

1) $4 \mathrm{NO}+\mathrm{O}_{2}+4 \mathrm{NH}_{3} \rightarrow 4 \mathrm{~N} 2+6 \mathrm{H}_{2} \mathrm{O}$

2) $\mathrm{NO}+\mathrm{NO}_{2}+2 \mathrm{NH}_{3} \rightarrow 2 \mathrm{~N} 2+3 \mathrm{H}_{2} \mathrm{O}$

3) $6 \mathrm{NO}_{2}+8 \mathrm{NH}_{3} \rightarrow 7 \mathrm{~N} 2+12 \mathrm{H}_{2} \mathrm{O}$

The first reaction is the predominant reaction. It shows that 1 mole of NH3 is consumed for each mole of NO removed. However, in an actual system, slightly more NH3 is injected than necessary for the desired NOx removal, to account for imperfect mixing. The excess NH3 which passes through the catalyst bed non-reacted is called NH3 slip. 


\subsubsection{Catalyst Specification}

The catalyst utilized is a honeycomb formed metal or clay plate with dynamic destinations made up of a blend of titanium and vanadium oxides. The catalyst is specific to upgrade NOx movement and minimize SO2 oxidation. The honeycomb shape is attractive to minimize stopping if particulates are available. The best temperature range for SCR Catalyst action and selectivity is from 700 o to $800^{\circ} \mathrm{F}$. Smelling salts are infused downstream from the burning zone and upstream of the catalyst.

\subsection{Detailed System model and Design of an SCR}

In this section, we mainly focus in Control part of NOx reduction technique using Selective Catalytic Reduction. In the current system, the two classical PID controllers (cascade controller) incorporating both feedforward and feedback control are used to reduce the NOx level by predicting the ammonia based on Fuel type, Fuel amount and Temperature of the process that time. Since this entire process takes place continuously, we can tell that this system is a continuous time system.

In the below figure, we can see that we have two PID controllers one is to reduce NOx value to the desired value and other PID controller is for Ammonia control valve to open or close the valve depending upon the set point and process value of $\mathrm{NH}_{3}$. 


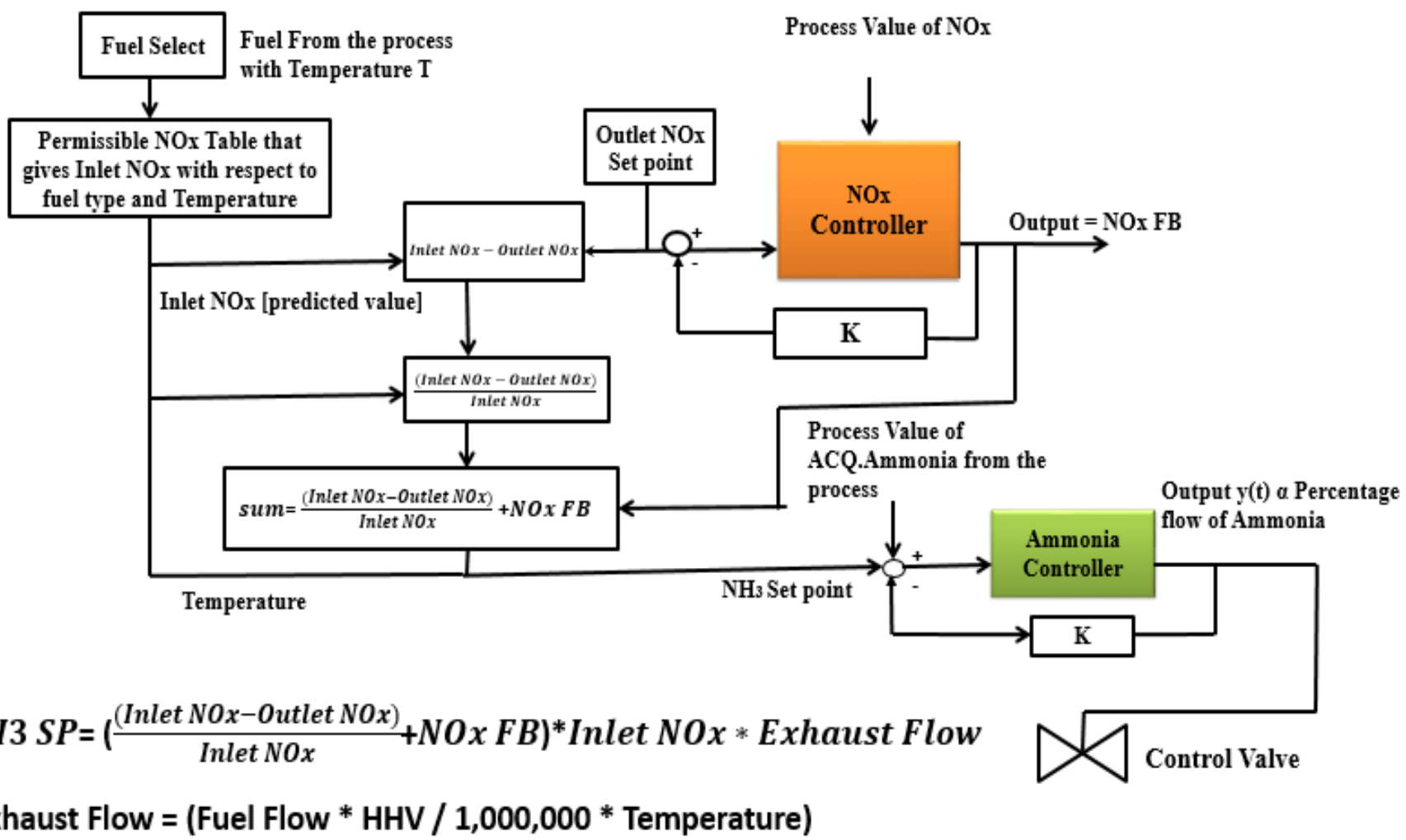

Figure 3: Detailed Control System Model of Selective Catalytic Reactor with cascade Controller

After determining the type of the fuel and temperature $T$, it is been compared with the Permissible NOx (Predefined table) from which the amount of NOx is predicted approximately based on Fuel type and temperature. The predicted inlet value of the NOx is called as "Inlet NOx" value is been fed into the percentage block. The NOx controller has a set point (according to EPA Standards) and process value $(\mathrm{pV})$, measured value coming from the SCR reactor. The output of the NOx controller is fed to the percentage block along with the difference between Inlet NOx and the Outlet NOx value.

The set point of the NH3 controller is determined by the value of NOx controller output. More is the set point of Ammonia Controller, value should be open more to have more Ammonia in the 
process to neutralize NOx. If the set point of the ammonia controller is lesser than that of process value of Ammonia controller.

The condition to be achieved in case of minimum NOx value are

Set point of NOx controller $\geq$ Process value of NOx controller and

Set point of NH3 controller $\leq$ Process value of NH3 Controller

For Ideal case, when desired NOx value is achieved in the process Set point of NOx controller $=$ Process value of NOx controller, no more ammonia is required to neutralize the NOx emission. Thus, the formula for Ammonia set point is given as follows

$$
\text { NH3 SetPoint }=\left(\frac{(\text { Inlet NOx-Outlet NOx })}{\text { Inlet NOx }}+\text { NOx FB }\right) * \text { Inlet NOx * Exhaust Flow }
$$

Exhaust Flow $=($ Fuel Flow $*$ HHV $/ 1,000,000 *$ Temperature $)$

It is called as cascade controller which combines feedforward (By predicting the value based on certain conditions) and feedback controller in the process.

\section{Problem Statement}

The main purpose of SCR control is to maintain NOx flow rate by modulating Ammonia flow rate. In the conventional controller, the cascade scheme involves both $\mathrm{NOx}$ and $\mathrm{NH}_{3}$ control which are independent PID controllers. This PID controller has certain drawbacks such as overshoots, high settling time, and increase in peak value and also higher cost function value represented by $\mathrm{J}$. In the proposed system, we are applying optimal control in the system and converting the system into linear quadratic Regulator (LQR) form such that we minimize the function 


$$
J=\int_{t 0}^{t 1}\left[x^{T} Q x(t)+u^{T}(t) R u(t)\right] d t
$$

Such that, the minimum cost obtained by the linear quadratic Regulator is lesser than nominal cost. The LQR has the capacity to overcome the disadvantages of the conventional PID Controller.

\section{$2.1 \quad$ Theoretical Definitions}

SCR: The Selective Catalytic Reduction is a process of converting Nitric Oxides (NOx) into Nitrogen and Water. This reaction takes place by making NOx react with Ammonia (NH3) to give NO2 and Water. This reaction takes place in the presence of a catalyst only where a catalyst just acts as the mediator to speed up the reaction but does not take place.

Optimal Control: An optimal control is a set of differential equations describing the paths of the control variables that minimize the cost function.

LQR (Linear Quadratic Regulator): This means that the settings of a controller governing either a machine or a process that are found by using a mathematical algorithm which minimizes a cost function with weighting factors supplied by a human. The "cost" (function) is often defined as a sum of the deviations of key measurements from their desired values.

PID Controller: A proportional-integral-derivative controller (PID controller) is a control loop feedback mechanism (controller) commonly used in industrial control systems. A PID controller continuously calculates an "error value" as the difference between a measured process variable and the desired set point.

Feedback Control: Feedback control is a control mechanism that uses information from measurements to manipulate a variable to achieve the desired result. 
Feed-forward Control: It is a term describing an element or pathway within a control system which passes a controlling signal from a source in its external environment, often a command signal from an external operator to a load elsewhere in its external environment. A control system which has only feed-forward behavior responds to its control signal in a pre-defined way without responding to how the load reacts; it is in contrast with a system that also has feedback, which adjusts the output to take account of how it affects the load, and how the load itself may vary unpredictably; the load is considered to belong to the external environment of the system.

Cascade Control: A primary or master controller generates a control effort that serves as the set point for a secondary or slave controller.

\subsection{Mathematical Tools}

MATLAB will be sufficient for mathematical analysis. The approach will be to find the mathematical representation of the system which we achieve by converting current transfer function into state-space representation. By that, we will be able to find out the performance and cost function of LQR model.

\subsection{Project Overview}

In Chapter 4, we are going to discuss NOx controller as a classical PID controller where we get performance graph and cost. In Chapter 5, we are going to discuss NOx controller as a Linear Quadratic Regulator and compare its minimum cost with the nominal cost. In Chapter 6, we are going to discuss $\mathrm{NH}_{3}$ controller as a classical PID controller where we get performance graph and cost. In Chapter 7, we are going to discuss $\mathrm{NH}_{3}$ controller as a Linear Quadratic Regulator and compare its minimum cost with the nominal cost. 
In Chapter 8, we are going to discuss the Results obtained in both existing and proposed method of both the controllers there by discussing advantages of the proposed method over existing method. In Chapter 9, we are going to discuss the future scope of this method that can be further extended.

In Appendix A and B MATLAB codes and simulation results are written for Chapters 5, 6, 7 and 8 respectively.

\section{NOx Controller as PID Controller}

In the existing system, the two classical PID controllers (cascade controller) incorporating both feedforward and feedback control are used to reduce the NOx level by predicting the ammonia based on Fuel type, Fuel amount, and Temperature and controlling the ammonia level based on that. This NH3 (Ammonia) reacts with NOx and gives harmless Nitrogen and water which greatly reduces the NOx level in the atmosphere.

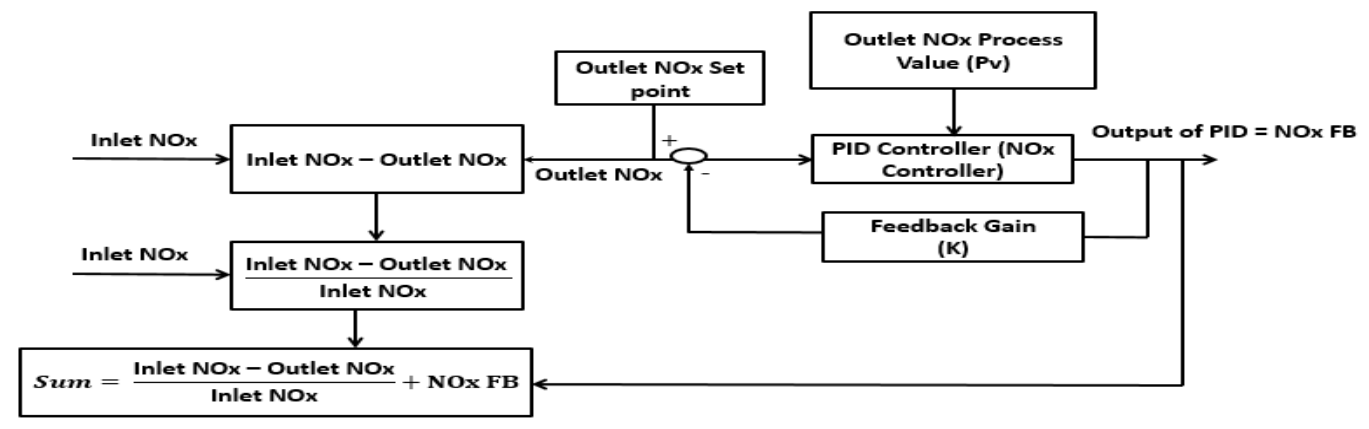

Figure 4 : Implementation of NOx controller as PID controller

In the proposed system, we are optimizing this whole process by depicting the mathematical model of the system. The NOx controller is a feedback controller that sets a reference of an NH3 flow rate in order to keep the NOx emission rate to NOx set point. This closed loop controller is effective in compensating calibration errors caused by NOx sensor drift. 
This controller has one input and one output and is a SISO (Single Input Single Output System). The input for the system is Inlet NOx and output is NOx FB which is added to the percentage reduction output. It has two states corresponding to Concentration of NOx and Concentration of Ammonia.

There are two states in this process namely $\mathrm{X}_{0}$ and $\mathrm{X}_{1}$ where $\mathrm{X}_{0}$ and $\mathrm{X}_{1}$ are initial and final states respectively corresponding to initial time $t_{0}$ and $t_{1}$ respectively.

$\mathrm{X}_{0}$ is a $2 \mathrm{x} 1$ Matrix

$\mathrm{X}_{1}$ is a $2 \mathrm{x} 1$ Matrix

$X 0=\frac{(\text { Concentration of NOX at } t=t 0)}{(\text { Concentration of } N H 3 \text { at } t=t 0)} \quad X 1=\frac{(\text { Concentration of NOX at } t=t 1)}{(\text { Concentration of } N H 3 \text { at } t=t 1)}$

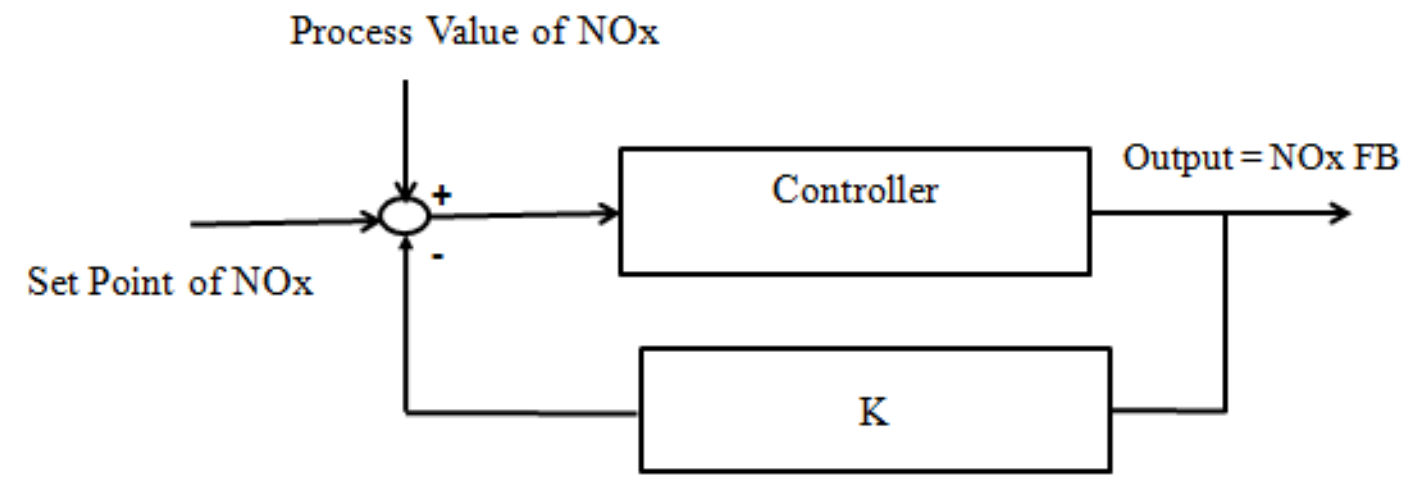

Figure 5: Feedback model of NOx controller as PID controller

The transfer function of the function is denoted by G(s). The Second-order system is generally categorized by the transfer function

$G(s)=\frac{b}{s^{2}+a s+b}$

We can re-write the above closed-loop transfer function as 


$$
G(s)=\frac{\omega_{n}^{2}}{s^{2}+2 \xi \omega_{n} s+\omega_{n}^{2}}
$$

$\xi$ is the damping factor and $\omega_{\mathrm{n}}$ is the natural frequency which generates the state-space description of the second order system $\mathrm{G}(\mathrm{s})$.

\subsection{Bode Plot of the System}

The plant transfer function $G 1(s)=\frac{62500}{\left(s^{2}+500 \mathrm{~s}+62500\right)}$ is obtained from the real time values for given $\xi$ and $\omega_{\mathrm{n}}$. Where frequency $\omega_{\mathrm{n}}$ is obtained Equation (4) by substituting $\xi=1$ and $\omega_{\mathrm{n}}$ $=250$ (Real time Values).

This system has damping factor $\xi=1$, it is a critically damped system with natural frequency $\omega_{n}=250 \mathrm{rad} / \mathrm{s}$.

Below is the tabulation that gives the sample real-time values of Inlet NOx, Outlet NOx, Fuel flow and Ammonia slip at certain temperature conditions in a Selective Catalytic Reactor.

Table 2 : Real time Values of Selective Catalytic Reactor process for reduction and control of NOx

\begin{tabular}{|c|c|c|c|c|c|c|c|c|c|c|}
\hline $\begin{array}{c}\text { Plant } \\
\text { Name }\end{array}$ & $\begin{array}{c}\text { Flue Gas } \\
\text { Flowrate } \\
\left(\mathrm{Nm}^{3} / \mathrm{hr}\right)\end{array}$ & $\begin{array}{c}\text { Temp } \\
\left({ }^{\circ} \mathrm{C}\right)\end{array}$ & $\begin{array}{c}\text { Inlet } \\
\text { NOx } \\
(\mathrm{ppm})\end{array}$ & $\begin{array}{c}\text { Outlet } \\
\text { NOx } \\
(\mathrm{ppm})\end{array}$ & $\begin{array}{c}\text { O2 } \\
(\%)\end{array}$ & $\begin{array}{c}\text { Removal } \\
\text { Efficiency } \\
(\%)\end{array}$ & $\begin{array}{c}\mathrm{NH}_{3} \\
\text { slip } \\
(\mathrm{ppm})\end{array}$ & $\begin{array}{c}\text { SOx } \\
(\mathrm{ppm})\end{array}$ & $\begin{array}{c}\mathrm{SO}_{3} \\
(\mathrm{ppm})\end{array}$ & $\begin{array}{c}\text { Particulate } \\
\left(\mathrm{mg} / \mathrm{Nm}^{3}\right)\end{array}$ \\
\hline FCCU \#1 & 75,600 & 369 & 300 & 60 & 1.9 & 80 & 5 & 200 & 20 & 60 \\
\hline FCCU \#2 & 83,000 & 380 & 500 & 250 & 1.0 & 50 & 10 & 120 & 10 & 200 \\
\hline FCCU \#3 & 530,367 & 288 & 350 & 28 & 2.0 & 92 & 20 & 25 & 3 & 120 \\
\hline FCCU \#4 & 147,500 & 360 & 160 & 16 & 2.0 & 90 & 5 & 586 & 46 & 520 \\
\hline FCCU \#5 & 171,600 & 360 & 250 & 50 & 2.0 & 80 & 5 & 1050 & 65 & 400 \\
\hline FCCU \#6 & 75,317 & 343 & 168 & 100 & 3.4 & 41 & 5 & 83 & 7 & 114 \\
\hline FCCU \#7 & 331,000 & 399 & 874 & 78 & 1.8 & 91 & 10 & 930 & 93 & 150 \\
\hline FCCU \#8 & 151,600 & 340 & 120 & 10 & 3.0 & 92 & 3 & 150 & 9 & 700 \\
\hline FCCU \#9 & 379,063 & 288 & 155 & 10 & 0.7 & 94 & 20 & 232 & 12 & 36 \\
\hline FCCU\#10 & 350,777 & 371 & 100 & 18 & 1.8 & 82 & 20 & 126 & 14 & 294 \\
\hline
\end{tabular}


Below are the given values from the real time process from which we find out the output of the PID controller to find out the set point of Ammonia.

Fuel Flow rate $=83.00$

Temperature as $380^{\circ} \mathrm{C}$

Inlet $\mathrm{NOx}=500 \mathrm{ppm}$

Outlet NOx $=250 \mathrm{ppm}$

Bode plots are the most useful way to represent the gain and phase of the system as a function of frequency (Frequency domain).

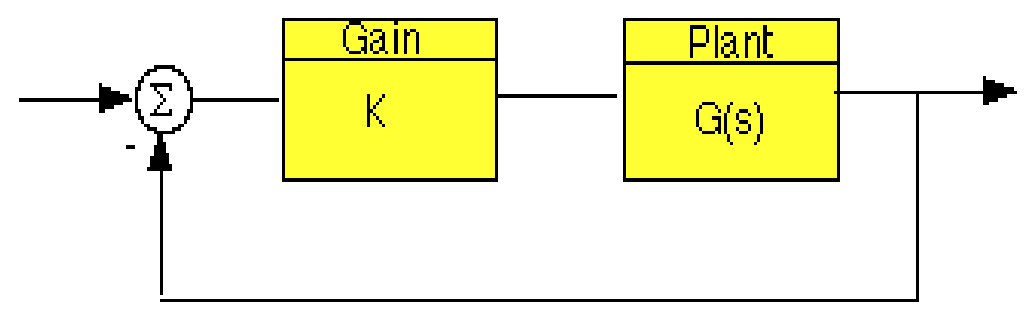

Figure 6: Model of a Basic Controller with Gain K

The block diagram resembles the above figure has a controller with transfer function $G 1(s)$ with gain $\mathrm{K}$.

The gain margin is defined as the change in open loop gain required making the system unstable. Higher the gain higher is the ability to withstand the changes in the system parameters. It is the gain margin is the difference between the magnitude curve and $0 \mathrm{~dB}$ at a point corresponding to frequency that gives - 180 deg (the phase crossover frequency)

NOTE: Unity gain in magnitude is equal to a gain in $\mathrm{dB}$. 
A phase margin is a change in open loop phase shift required to make a closed loop system unstable. It is the difference in phase between phase curve and -180 degree at the point corresponding to the frequency giving $0 \mathrm{~dB}$.

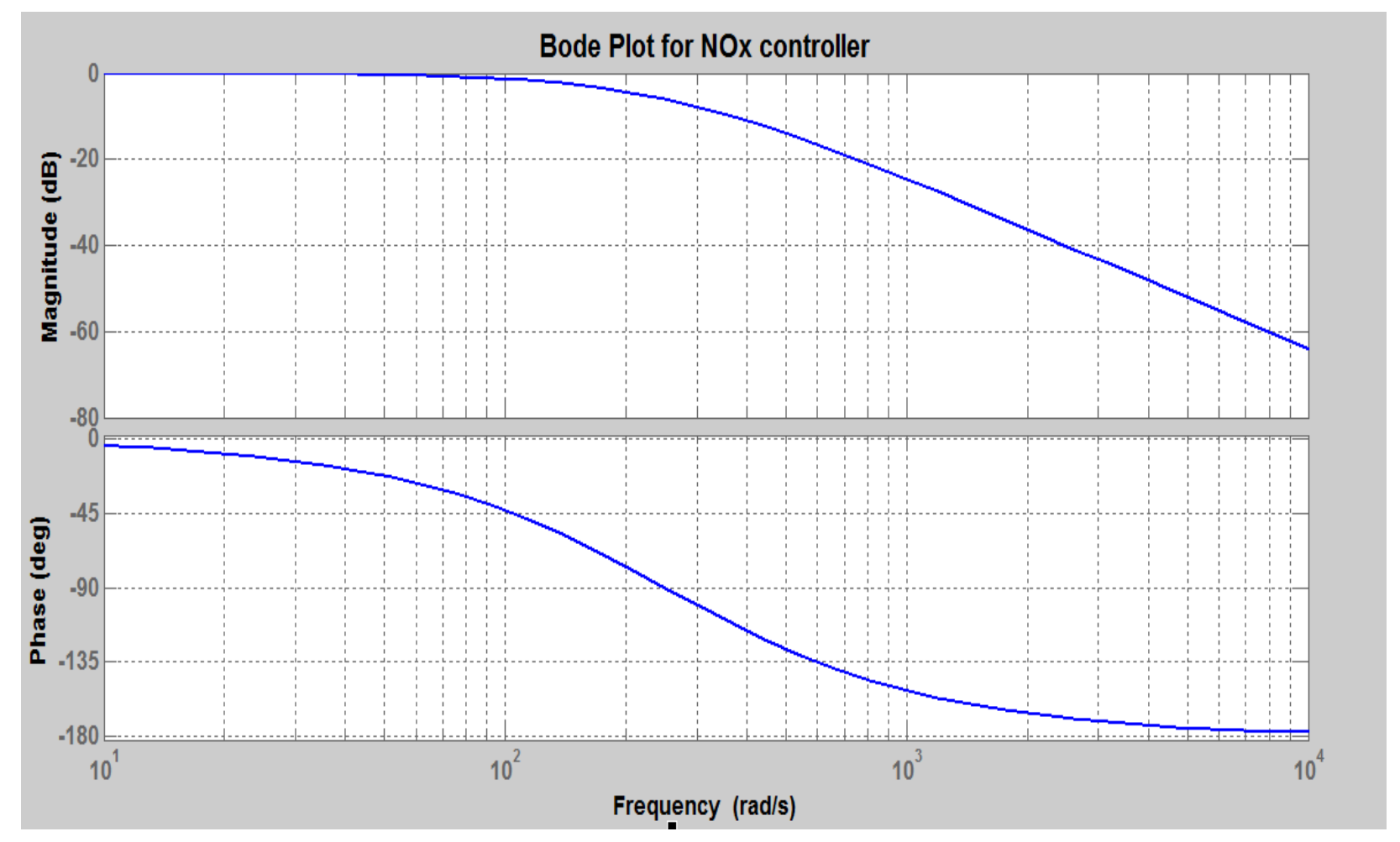

Figure 7: Bode Plot for NOx Controller

\subsection{Computing the Performance of PID Controller [NOx Controller]}

The performance of PID controller is obtained by adding a unity feedback i.e $\mathrm{H}=1$. To calculate the state-space model zero initial state is assumed. This step response can be used for Continuous-time or discrete time systems.

This process is a continuous-time process with single input and the single output. The duration of simulation is determined automatically which is based on the system poles and zeros. 
Let $\mathrm{C}(\mathrm{S})$ be the output, $\mathrm{R}(\mathrm{S})$ be the input and $G 1(s)$ be the plant, we get the transfer function with unity feedback as

$$
\text { Transfer Function }=\frac{C(S)}{R(S)}=\frac{G 1(S)}{(1+G 1(S))}
$$

$$
G 1(s)=\frac{62500}{\left(s^{2}+500 s+62500\right)}
$$

In the above figure the unity feedback curve is indicated by the Green color curve giving steady state error with respect to the transfer function.

The general form of a PID control is

$$
c(s)=K_{p}+\frac{K_{i}}{s}+K_{d} s
$$

Where $K_{p}, K_{i}$ and $K_{d}$ are the proportional, Integral and Derivative constants respectively.

We have obtained the overall transfer function by multiplying $G 1(s)$ and $C(s)$

$$
G 1(s) * C(s)=\frac{62500}{\left(s^{2}+500 s+62500\right)} * \frac{\left(K_{d} s^{2}+K_{p} s+K_{i}\right)}{s}
$$

In our case, we have obtained as $\quad\left(62500 K_{d} s^{2}+62500 K_{p} s+62500 K_{i}\right)$

$$
s^{3}+\left(500+62500 K_{d}\right) s^{2}+62500\left(1+K_{p}\right) s+62500 K_{i}
$$

The closed loop characteristic equation should be in the form

$$
s^{3}+\left(p+A K_{d}\right) s^{2}+A K_{p} s+A K_{i}
$$

The poles can be assigned with three controller parameters, and a 3rd order closed-loop system. Using $\left(\xi, \omega_{n}\right)$ parameterization with the third pole at $-\alpha \omega_{n}$, the characteristic equation is

$$
\left(s^{2}+2 \xi \omega_{n} s+\omega_{n}^{2}\right)\left(s+\alpha \omega_{n}\right)
$$


By rewriting the above equation we get

$$
s^{3}+(2 \xi+\alpha) \omega_{n} s^{2}+(2 \xi \alpha+1) \omega_{n} s+\alpha \omega_{n}^{3}
$$

Comparing the above equation by the denominator of our transfer function,

$$
s^{3}+\left(500+62500 K_{d}\right) s^{2}+62500\left(1+K_{p}\right) s+62500 K_{i}
$$

Where $P=500$ and $A=2 \omega_{n}=62500$. The gain values $K_{p}, K_{d}$ and $K_{i}$ values in terms of general equation is

$K_{d}=\frac{(2 \xi+\alpha) \omega_{n}-P}{A} \quad K_{p}=\frac{(2 \xi \alpha+1) \omega_{n}^{2}}{A}-1 \quad K_{i}=\frac{(\alpha) \omega_{n}^{3}}{A}$

According to our values the $K_{p}, K_{d}$ and $K_{i}$ according to our transfer function is as follows

$$
K_{d}=\frac{(2 \xi+\alpha) \omega_{n}-500}{62500} \quad K_{p}=\frac{(2 \xi \alpha+1) \omega_{n}^{2}}{62500}-1 \quad K_{i}=\frac{(\alpha) \omega_{n}^{3}}{62500}
$$

By substituting the values for $\boldsymbol{\xi}=\mathbf{1}$ and $\boldsymbol{\omega}_{\boldsymbol{n}}=\mathbf{2 5 0}$, we should select $\alpha$ value such that it is less than 1 $(\alpha<<1)$ so we chose $\boldsymbol{\alpha}$ as $\mathbf{0 . 1}$, we get $\boldsymbol{K}_{\boldsymbol{d}}=\mathbf{4} * \mathbf{1 0}^{-\mathbf{4}}, \boldsymbol{K}_{\boldsymbol{p}}=\mathbf{0 . 2}$ and $\boldsymbol{K}_{\boldsymbol{i}}=\mathbf{2 5}$. The graph has been plotted in Figure 8 as per the above values.

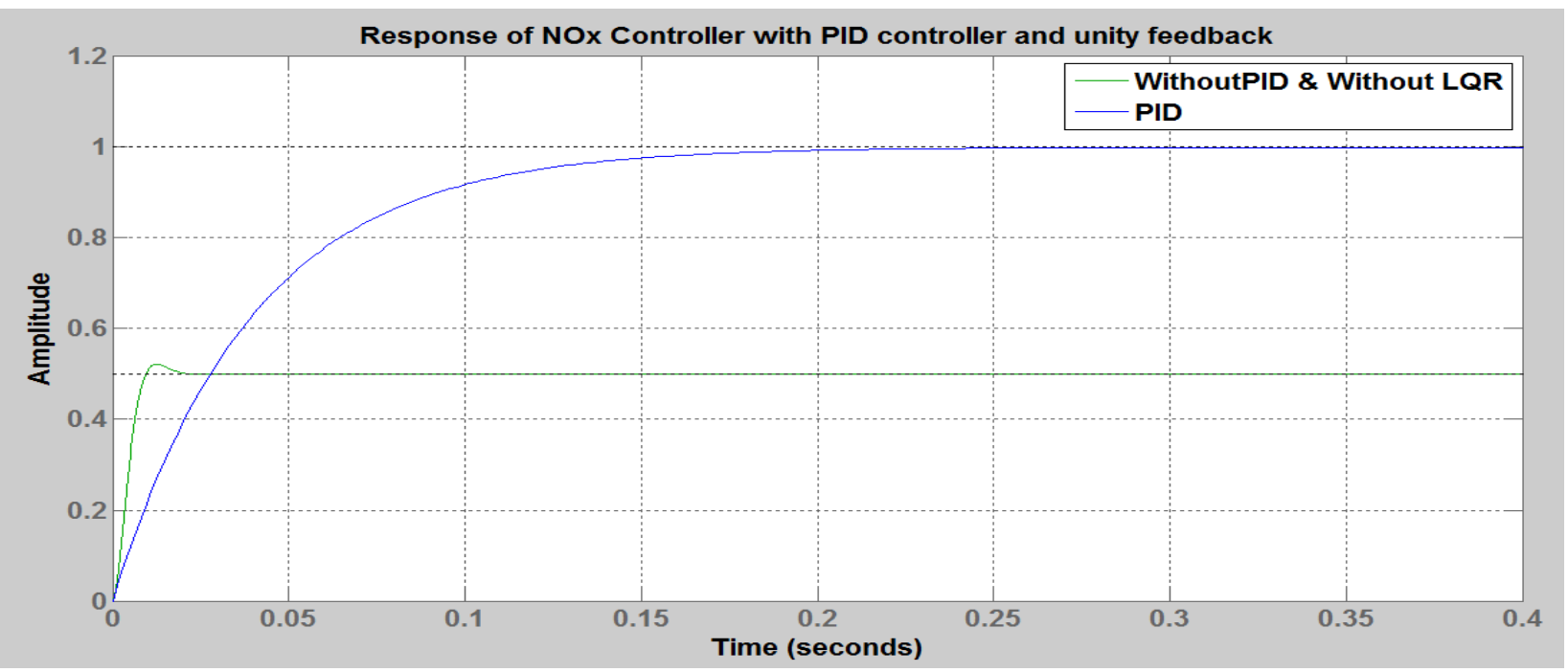

Figure 8: Performance Graph of NOx Implementing PID Controller with and without PID Controller 


\subsubsection{Generating State Feedback Controller}

To compute the nominal cost of an LQR system first step is to find state space equation of the transfer function $\mathrm{G}_{1}(\mathrm{~s})$. We have to construct a state space model based on the model representing the continuous time state-space model and the general form is given below:

$\dot{\mathrm{X}}(t)=A x(t)+B u(t)$

$Y(t)=C x(t)+D u(t)$

Where $\mathrm{A}$ is the state or system matrix

$\mathrm{B}$ is the input matrix

$\mathrm{C}$ is the output matrix

$\mathrm{D}$ is the Feedforward matrix

$\dot{\mathrm{X}}(t)$ is the state vector and $\dot{\mathrm{X}}(t)=\frac{d}{d x} x(t)$

$Y(t)$ is the output vector.

The state space matrices we obtained from MATLAB simulations are

$$
\begin{aligned}
& \mathrm{A} 1=\left[\begin{array}{cc}
-500 & -244.1 \\
256 & 0
\end{array}\right] \\
& \mathrm{B} 1=\left[\begin{array}{c}
16 \\
0
\end{array}\right] \\
& \mathrm{C} 1=\left[\begin{array}{ll}
0 & 15.26
\end{array}\right] \\
& \mathrm{D} 1=[0]
\end{aligned}
$$

Identity matrix, $I=\left[\begin{array}{ll}1 & 0 \\ 0 & 1\end{array}\right]$ 


\subsubsection{Stability of the Function:}

The main specification of an Optimal Control Design is to obtain minimum cost of the system. The pole locations are not the required specifications but the stability of the system should be ensured. In order to check the stability of the system, we find the poles of the system and also make sure the poles are controllable. The transfer function of the system can also be written as

$$
G(s)=\frac{(s-Z 1)(s-Z 2)}{(s-P 1)(s-P 2)}
$$

Where $\mathrm{Z} 1$ and $\mathrm{Z} 2$ are zeroes and $\mathrm{P} 1, \mathrm{P} 2$ are poles of the system respectively. The denominator of the transfer function is the characteristic polynomial equation obtained by $\operatorname{det}(S I-A)$

$$
\lambda(s)=|s I-A|
$$

To analyze the system's lyapunov stability we equate $\lambda(s)=0$

$$
\begin{aligned}
& \text { We get, }|S I-A|=\left[\begin{array}{ll}
S & 0 \\
0 & S
\end{array}\right]-\left[\begin{array}{cc}
-500 & -244.1 \\
256 & 0
\end{array}\right] \\
& =\left[\begin{array}{cc}
S+500 & 244.1 \\
-256 & S
\end{array}\right]
\end{aligned}
$$$$
S 1=-250 \text { and } S 2=-250
$$

The system is stable since both the poles are negative.

Define $u=\left[\begin{array}{ll}G 1 & G 2\end{array}\right]=-G X$ then

$$
\begin{aligned}
\mathbf{A c}= & A-B K=\left[\begin{array}{cc}
-500 & -244.1 \\
256 & 0
\end{array}\right]-\left[\begin{array}{c}
16 \\
0
\end{array}\right]\left[\begin{array}{ll}
G 1 & G 2
\end{array}\right] \\
& =\left[\begin{array}{cc}
-500-16 G 1 & -244-16 G 2 \\
256 & 0
\end{array}\right]
\end{aligned}
$$


So then we have that

$$
\begin{array}{r}
\operatorname{det}\left(s I-A_{C}\right)=\left[\begin{array}{ll}
S & 0 \\
0 & S
\end{array}\right]-\left[\begin{array}{cc}
-500-G 1 & -244.1-16 G 2 \\
256 & 0
\end{array}\right] \\
=\left[\begin{array}{cc}
S+500+G 1 & 244.1+16 G 2 \\
-256 & S
\end{array}\right] \\
\mathrm{S}(\mathrm{S}+500+\mathrm{G} 1)+256(244.1+16 \mathrm{G} 2)=0
\end{array}
$$

The poles at $p=-250$ and -250 which can be written as $(S+250)(S+250)$ is been compared with the above equation in order to obtain the gain value.

We get gain as $G=\left[\begin{array}{ll}0 & 0.0025\end{array}\right]$ where we have to check the system for controllability and observability.

\section{Controllability Test:}

In order to exhibit the desired operation in a dynamic system under control input, the system must be controllable. If the system state changes by changing the input of the system, it is said to be controllable.

If the system is said to be controllable if $\operatorname{det}(C O) \neq 0$

$$
\begin{aligned}
& \mathrm{CO}=\left[\begin{array}{lll}
\mathrm{B} & \mathrm{AB} & \mathrm{A}^{2} \mathrm{~B} \ldots \ldots \mathrm{A}^{\mathrm{n}-1} \mathrm{~B}
\end{array}\right] \\
& \mathrm{B}=\left[\begin{array}{c}
16 \\
0
\end{array}\right] \quad \mathrm{AB}=\left[\left[\begin{array}{cc}
-500 & -244.1 \\
256 & 0
\end{array}\right]\right] \cdot\left[\begin{array}{c}
16 \\
0
\end{array}\right]=\left[\begin{array}{c}
-8000 \\
4096
\end{array}\right] \\
& \mathrm{CO}=\left[\begin{array}{ll}
\mathrm{B} & \mathrm{AB}
\end{array}\right]=\left[\begin{array}{cc}
16 & -8000 \\
0 & 4096
\end{array}\right] \\
& \operatorname{det}(C O)=65536 \neq 0
\end{aligned}
$$


Thus the system is controllable.

\section{Observability Test:}

The system must be observable to see the happenings inside any system.

If the system is said to be observable if $\operatorname{det}(O B) \neq 0$

$$
\begin{aligned}
& \mathrm{OB}=\left[\begin{array}{c}
C \\
C A \\
C A \\
\cdot \\
\cdot \\
C A^{n-1}
\end{array}\right] \\
& \mathrm{C}=\left[\begin{array}{ll}
0 & 15.26
\end{array}\right] \\
& \mathrm{CA}=\left[\begin{array}{ll}
0 & 15.26
\end{array}\right] \cdot\left[\begin{array}{cc}
-500 & -244.1 \\
256 & 0
\end{array}\right]=\left[\begin{array}{ll}
3906.56 & 0
\end{array}\right] \\
& \mathrm{OB}=\left[\begin{array}{cc}
0 & 15.26 \\
3906.56 & 0
\end{array}\right] \\
& \operatorname{det}(O B)=0-59614=-59614 \neq 0
\end{aligned}
$$

Thus the system is observable.

By finding the controllability and observability we ensure the stability of an unstable system by feedback or an optimal control.

\subsection{Computation of Nominal Cost Function in NOx controller}

We use Lyapunov equation to find the nominal cost of the system. A dynamic system described by a differential equation and finding a cost function is essential. Control will allow the 
system to converge towards the desired state, handled through a feedback input depending upon the state of the system.

We need to minimize

$$
J=\int_{t 0}^{t 1}\left[x^{T} Q x(t)+u^{T}(t) R u(t)\right] d t
$$

Where $\mathrm{Q}$ is a positive semi-definite matrix attributed to state

$\mathrm{R}$ is a positive definite matrix attributed to the input, $\mathrm{t} 1$ and $\mathrm{t} 2$ are initial and final time respectively

$$
\text { We know that } u(t)=-F(t) x(t)
$$

When $t \rightarrow \infty$ then $u=-F x(t)$ where $F$ is the constant feedback gain of the system.

$$
F=-R^{-1} B^{T} K
$$

$K$ is nothing but the algebraic Riccati equation.

\section{Nominal Cost function Solution:}

We have got $A_{c}=A-B G$ closed loop system having Algebraic Riccati equation in the form $0=A^{T} P+P A-P S P+Q$

Where A, S and Q are symmetric matrices defined by the system. We define the Hamiltonian matrix as $\mathrm{H}$ which is a $2 \times 2$ matrix

$$
\mathrm{H}=\left[\begin{array}{cc}
A & -S \\
-Q & -A^{\wedge} T
\end{array}\right] \text { and } \mathrm{P}=\left[\begin{array}{ll}
P 1 & P 2 \\
P 2 & P 3
\end{array}\right]
$$


By rewriting Riccati equation,

$$
0=P A_{c}+A_{c}^{T}+Q_{c}
$$

We assume $Q_{c}=\left[\begin{array}{ll}1 & 0 \\ 0 & 0\end{array}\right], G=\left[\begin{array}{ll}0 & 0.0025\end{array}\right]$ and $R=[0.00001]$

Using MATLAB, using lyapunov function we found the value of $Q_{c}=\left[\begin{array}{cc}1.000 & 0 \\ 0 & 0\end{array}\right]$

After obtaining the value of $\mathrm{Q}_{c}$, substitute in the equation to find the value of $\mathrm{P}$

$\mathrm{P}=\left[\begin{array}{ll}P 1 & P 2 \\ P 2 & P 3\end{array}\right]=\left[\begin{array}{cc}0.0010 & 0 \\ 0 & 0.0010\end{array}\right]$

The nominal cost function is given by,

$$
J=\frac{1}{2} \cdot X(0) \cdot P \cdot X(0)
$$

Where we have defined $X(0)$ based on the concentration of NOx and Ammonia at the initial state.

$$
\begin{gathered}
X(0)=\left[\begin{array}{c}
30 \\
0
\end{array}\right] \\
J=\frac{1}{2} \cdot\left[\begin{array}{ll}
30 & 0
\end{array}\right] \cdot\left[\begin{array}{cc}
0.0010 & 0 \\
0 & 0.0010
\end{array}\right] \cdot\left[\begin{array}{c}
30 \\
0
\end{array}\right] \\
J=0.4500
\end{gathered}
$$

Thus we have cost function value to be 0.4500 


\section{Implementing LQR Technique in NOx Controller}

The Linear Quadratic Regulator is used in Optimal Control where our main aim is to minimize the energy of a system which gives the minimized cost. It is the special case of an optimal control problem which is of particular importance arises when the objective function is a quadratic function of $\mathbf{x}$ and $\mathbf{u}$, and the dynamic equations are linear. The resulting feedback law in this case is known as LQR and the performance Index is given by

$$
\mathrm{J}=\frac{1}{2} x\left(t_{f}\right)^{T} s_{f} x\left(t_{f}\right)+\frac{1}{2} \int_{t 0}^{t f}\left(x(t)^{T} Q x(t)+\left(u(t)^{T} R u(t)\right) d t\right.
$$

Where $s_{f}$ and $Q$ are the positive definite matrices and the system obey the law

$$
\dot{\mathrm{X}}(t)=A x(t)+B u(t), x\left(t_{0}\right)=x_{0}
$$

Where $\mathrm{A}$ is the system matrix and $\mathrm{B}$ is the input matrix

The Optimal control law can be expressed as a linear state feedback:

$$
u(t)=-K(t) x(t)
$$

And the feedback gain is given by $K(t)=R^{-1} B^{T} S(t)$ and

$S(t)$ is the solution to the Riccati equation

$$
S=A^{T} S+S A-S B R^{-1} B^{T} S+Q \quad \text { and } \quad S\left(t_{f}\right)=s_{f}
$$

In this particular case where $t_{f} \rightarrow \infty$ provided $(A, B)$ is stabilizable, the Riccati equation converges to a limiting solution $S$ and the constant feedback gain is given by $K$ given by

$$
K=R^{-1} B^{T} S
$$


Where $S$ is the positive definite solution of algebraic Riccati Equation

$$
A^{T} S+S A-S B \dot{R}^{-1} B^{T} S+Q=0
$$

If the pair $(A, C)$ is observable where $C^{T} C=Q$, then the closed loop system

$$
\dot{\mathrm{X}}=(\mathrm{A}-\mathrm{BK}) \mathrm{X}
$$

This closed loop system is asymptotically stable provides a way of stabilizing any linear system that is stabilizable.

We find the solution for S (Energy minimization) in order to find the minimum cost of the Linear Quadratic Regulator.

\subsection{Computing Minimum Cost in NOx Controller}

The figure shows the general form of a feedback configuration of an LQR problem which is a continuous-time system form:

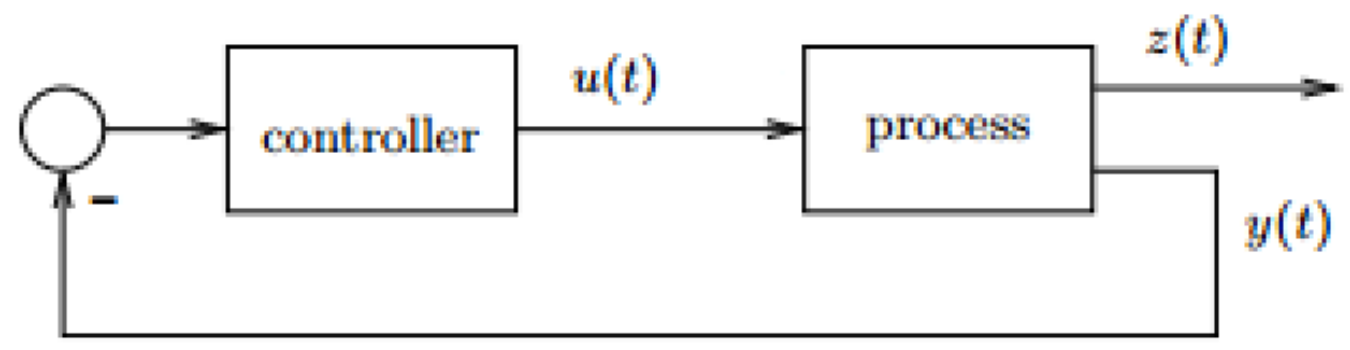

The measured output $y(t)$ measured is available for control

$Z(t)$ is the controlled output and the LQR problem is defined as follows:

$$
J_{L Q R}=\int_{0}^{\infty}\|z(t)\|^{2}+\rho\|u(t)\|^{2} d t
$$


Where $\rho$ is a positive constant and the term $\int_{0}^{\infty}\|z(t)\|^{2}$

Corresponds to the energy of the controlled output and the term to the energy of the control signal.

$$
\int_{0}^{\infty}\|u(t)\|^{2}
$$

We have to place the poles such that closed-loop system optimizes the cost function

$$
J_{L Q R}=\int_{0}^{\infty}\left[x(t)^{T} Q x(t)+u(t)^{T} R u(t)\right) d t
$$

Where $x^{T} Q x$ is the state cost with weight $Q$.

$u^{T} Q u$ Is the control cost with weight $R$.

Equation (18) solves the Algebraic Riccati equation where $K$ is the gain, $\mathrm{S}$ is the output of the LQR and $\mathrm{e}$ is a non-singular value. Regardless of the values of $\mathrm{Q}$ and $\mathrm{R}$, the cost function has a unique minimum that can be obtained by solving Algebraic Riccati Equation. The parameters Q and R can be used as design parameters to fine tune the state variables and the control signals.

Higher the value of R means you try to stabilize the system with less (weighted) energy called expensive control strategy.

Smaller the value for R means you don't want to penalize the control signal called cheap control strategy.

Ensuring above conditions we have chosen $Q$ matrix as $\left[\begin{array}{ll}1 & 0 \\ 0 & 0\end{array}\right]$ and $R=[0.00001]$ Output of LQR, $S=\left[\begin{array}{cc}0.1791 & 0 \\ 0 & 0.1707\end{array}\right]$. Minimum cost $J *$ is given as 


$$
\begin{aligned}
& J *=\frac{1}{2} X^{T} S X \\
& J *=0.0806
\end{aligned}
$$

The minimum cost or the cost corresponding to the minimum energy is 0.0806

By comparing the value of $J$ and $J *$ we can conclude that $J *<J$. Thus, the nominal cost is lesser than that of Minimum cost.

\subsection{Comparison of PID and LQR Performance in NOx Controller}

We have recorded the performance of PID and LQR controller and the graph is given below.

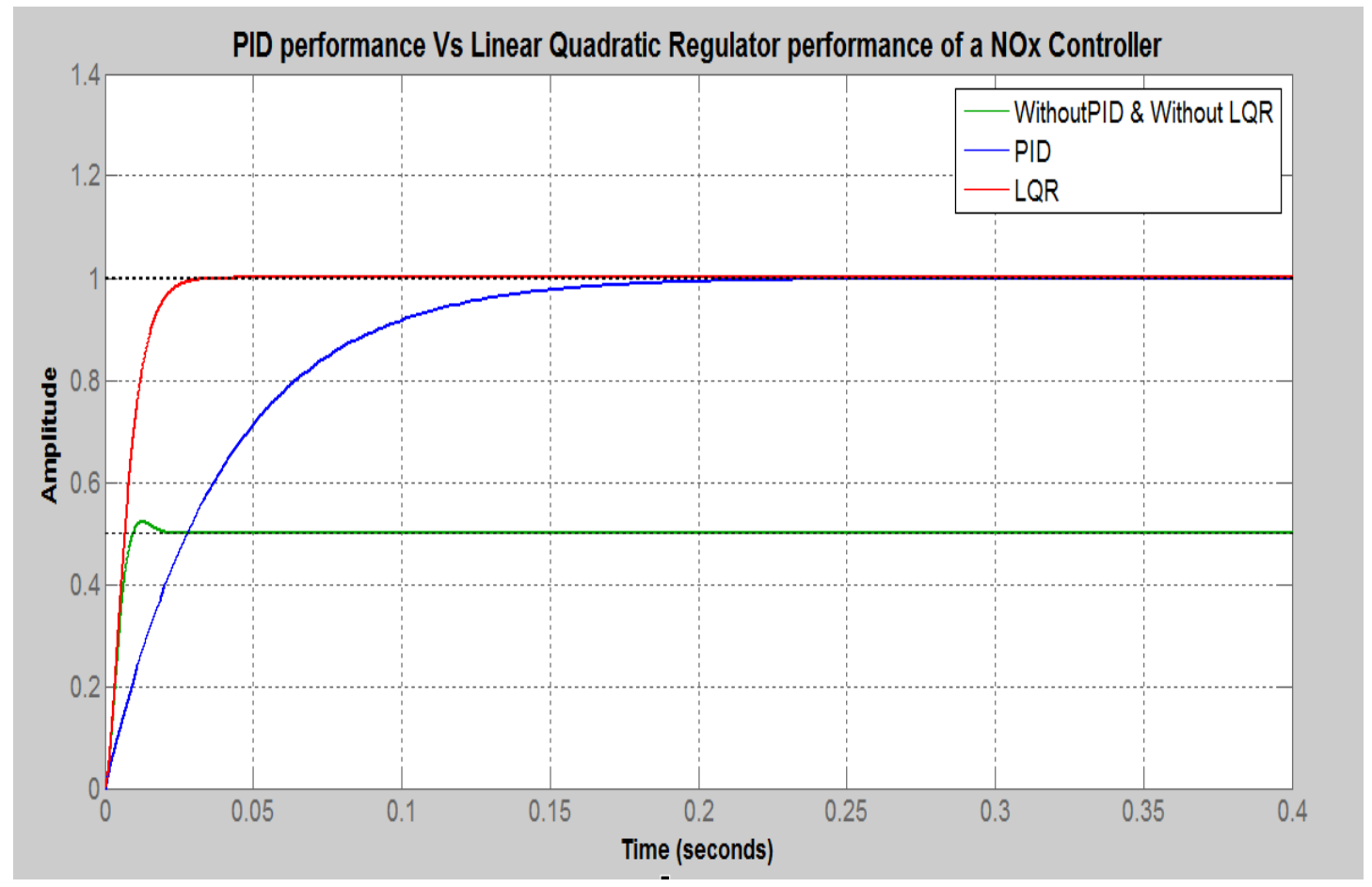

Figure 9: PID performance Vs Linear Quadratic Regulator performance of a NOx Controller. The settling time of a PID Controller is 0.226 seconds whereas the settling time of LQR is only 0.0498 sec.

Linear Quadratic Regulator design method has following benefits as follows:

1) LQR is an optimal control Regulator which tracks trajectory better than PID. 
2) LQR being an optimal controller provides smallest error to its input and minimizes the control output. LQR is straightforward to use in case of multi-variable systems and the design procedure is same as that of SISO (Single Input Single Output systems).

3) LQR technique minimizes the Energy of the system which minimizes the overall cost and its output settles faster with less overshoot.

4) It is easier to prioritize inputs with respect to states at a particular time instant.

5) In the Linear Quadratic Regulator we attain less peak value and we automatically get stabilized controllers.

\section{Ammonia Controller as PID Controller}

Ammonia Controller in the system attached to a control valve is employed to control the flow of Ammonia. The set point of this controller is obtained from the output of the NOx controller and the formula to find the set point of Ammonia is

$$
\begin{gathered}
\text { NH3 SP }=\left(\frac{(\text { Inlet NOx-Outlet NOx })}{\text { Inlet NOx }}+N O x \text { FB }\right) * \text { Inlet NOx } * \text { Exhaust Flow } \\
\text { Exhaust Flow }=(\text { Fuel Flow } * H H V / 1,000,000 * \text { Temperature })
\end{gathered}
$$

NH3 SP = Set point of Ammonia Controller

Inlet NOx $=$ SCR inlet concentration based on Fuel flow, Fuel Type and Temperature (PPM)

Outlet NOx $=$ Process value of NOx (PPM)

NOx FB $=$ Output from outlet NOx feedback PID controller output

Exhaust Flow $=$ Flue gas flow rate in MMSCFH

Fuel Flow $=$ Natural Gas flow rate in SCFH 
$\mathrm{K}=$ Exhaust Gas Constant in SCF

When Inlet NOx, Outlet NOx and the temperature is already known from the process, we have calculated NOx FB (output of the NOx controller).

The block diagram here shows the PID controller in the existing system which is used to control the amount of Ammonia (NH3) required for the process. This amount of NH3 flowing from the control valve is based on the Set point of NH3 got from the formulae above.

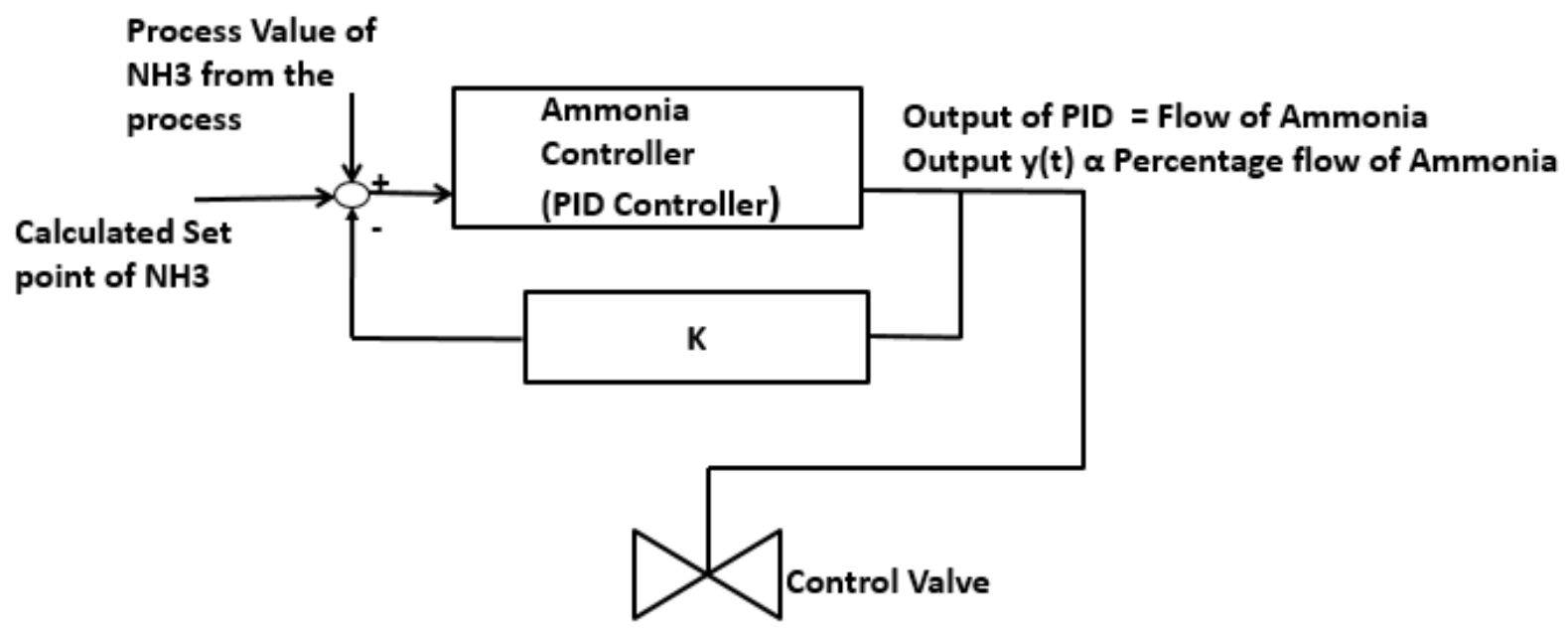

Figure 10: Figure Showing how NOx Controller as a PID Controller

The opening or closing of the Ammonia control valve depends upon the difference in Set point and the process value. If the set point if more than the process value, we require more Ammonia in the process to react with NOx. 
Incase if the process value of NH3 is more than that of Set point we require less Ammonia. Thus, we can conclude that set point of Ammonia is proportional to the Flow of Ammonia from the control valve.

\subsection{Bode Plot of the system}

The transfer function $G 2(s)=\frac{2.573}{\left(s^{2}+3.208 s+2.573\right)}$ is obtained from the real time values for given $\xi$ and $\omega_{\mathrm{n}}$ where frequency $\omega_{\mathrm{n}}$ is obtained from the Equation(21) by substituting $\xi=1$ and $\omega_{\mathrm{n}}=1.604$ which is critically damped system..

This system has damping factor $\xi=1$, it is a critically damped system with natural frequency $\omega_{\mathrm{n}}=1.604$ $\mathrm{rad} / \mathrm{s}$. The below graph shows the magnitude and phase margin with respect to frequency to ensure the stability of the system

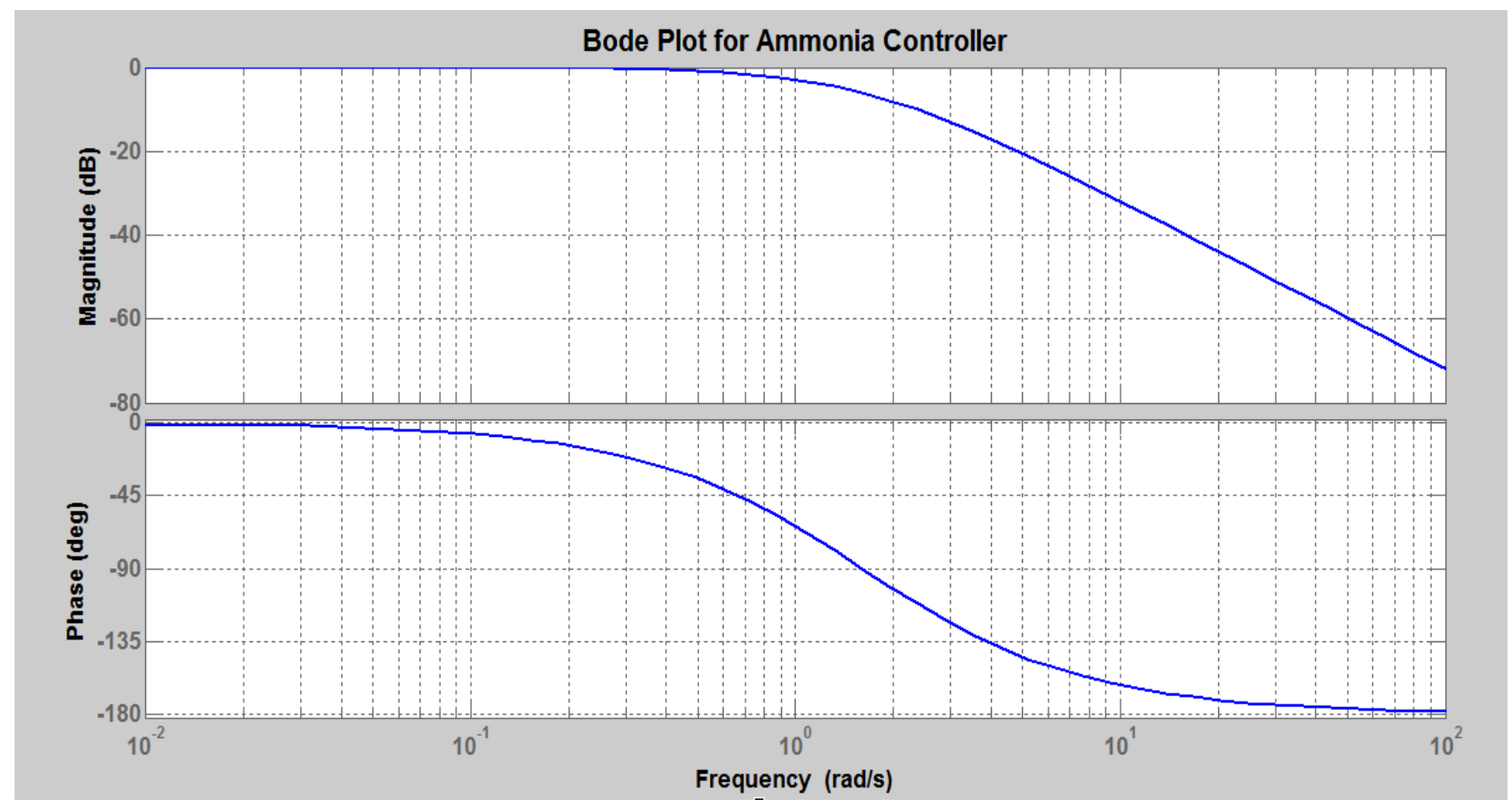

Figure 11: Bode Plot of a NH3 Controller to find Stability 


\subsection{Computing the Performance of PID Controller [NH3 Controller]}

A unity feedback i.e $\mathrm{H}=1$ is added to simulate the performance. To calculate the state-space model zero initial state is assumed for Continuous-time system.

Let $\mathrm{C}(\mathrm{S})$ be the output, $\mathrm{R}(\mathrm{S})$ be the input and $G 2(s)$ be the controller, we get the transfer function with unity feedback as

$$
\begin{aligned}
& \text { Transfer Function }=\frac{C(S)}{R(S)}=\frac{G 1(S)}{(1+G 1(S))} \\
& G 2(s)=\frac{2.573}{\left(s^{2}+3.208 s+2.573\right)}
\end{aligned}
$$

In the above figure the unity feedback curve is indicated by the Green color curve giving steady state error with respect to the transfer function.

The general form of a PID control is

$$
C(s)=K_{p}+\frac{K_{i}}{\mathrm{~s}}+K_{d} s
$$

Where $K_{p}, K_{i}$ and $K_{d}$ are the proportional, Integral and Derivative constants respectively.

We have obtained the overall transfer function by multiplying $G 2(s)$ and $C(s)$

$$
G 2(s) * C(s)=\frac{2.573}{\left(s^{2}+3.208 \mathrm{~s}+2.573\right)} * \frac{\left(K_{d} s^{2}+K_{p} s+K_{i}\right)}{\boldsymbol{s}}
$$

In our case, we have obtained as $\quad\left(2.573 K_{d} s^{2}+2.573 K_{p} s+2.573 K_{i}\right)$

$$
s^{3}+\left(3.208+2.573 K_{d}\right) s^{2}+2.573\left(1+K_{p}\right) s+2.573 K_{i}
$$

The closed loop characteristic equation is

$$
s^{3}+\left(p+A K_{d}\right) s^{2}+A K_{p} s+A K_{i}
$$

The poles can be assigned with three controller parameters, and a 3rd order closed-loop system. Using 
$\left(\xi, \omega_{n}\right)$ parameterization with the third pole at $\alpha \omega_{n}$ the characteristic equation is

$$
\left(s^{2}+2 \xi \omega_{n} s+\omega_{n}^{2}\right)\left(s+\alpha \omega_{n}\right)
$$

By rewriting the above equation we get

$$
s^{3}+(2 \xi+\alpha) \omega_{n} s^{2}+(2 \xi \alpha+1) \omega_{n} s+\alpha \omega_{n}^{3}
$$

Comparing the above equation by the denominator of our transfer function,

$$
s^{3}+\left(3.208+2.573 K_{d}\right) s^{2}+2.573\left(1+K_{p}\right) s+2.573 K_{i}
$$

Where $\mathrm{P}=3.208$ and $A=2 \omega_{n}$ and gains $K_{p}, K_{d}$ and $K_{i}$ values in terms of general equation is

$$
K_{d}=\frac{(2 \xi+\alpha) \omega_{n}-P}{A} \quad K_{p}=\frac{(2 \xi \alpha+1) \omega_{n}^{2}}{A}-1 \quad K_{i}=\frac{(\alpha) \omega_{n}^{3}}{A}
$$

According to our values the $K_{p}, K_{d}$ and $K_{i}$ according to our transfer function is as follows

$$
K_{d}=\frac{(2 \xi+\alpha) \omega_{n}-3.208}{2.573} \quad K_{p}=\frac{(2 \xi \alpha+1) \omega_{n}^{2}}{2.573}-1 \quad K_{i}=\frac{(\alpha) \omega_{n}^{3}}{2.573}
$$

By substituting the values for $\xi=\mathbf{1}$ and $\boldsymbol{\omega}_{\boldsymbol{n}}=\mathbf{1 . 6 0 4}$, we should select $\alpha$ value such that it is less than $1(\alpha<<1)$ so we chose $\boldsymbol{\alpha}$ as $\mathbf{0 . 8}$, we get $K_{\boldsymbol{p}}=\mathbf{0 . 2}, \boldsymbol{K}_{\boldsymbol{d}}=\mathbf{1 . 1 6 0 4}$ and $\boldsymbol{K}_{\boldsymbol{d}}=\mathbf{0 . 0 6 2 3}$. The performance graph is given below 


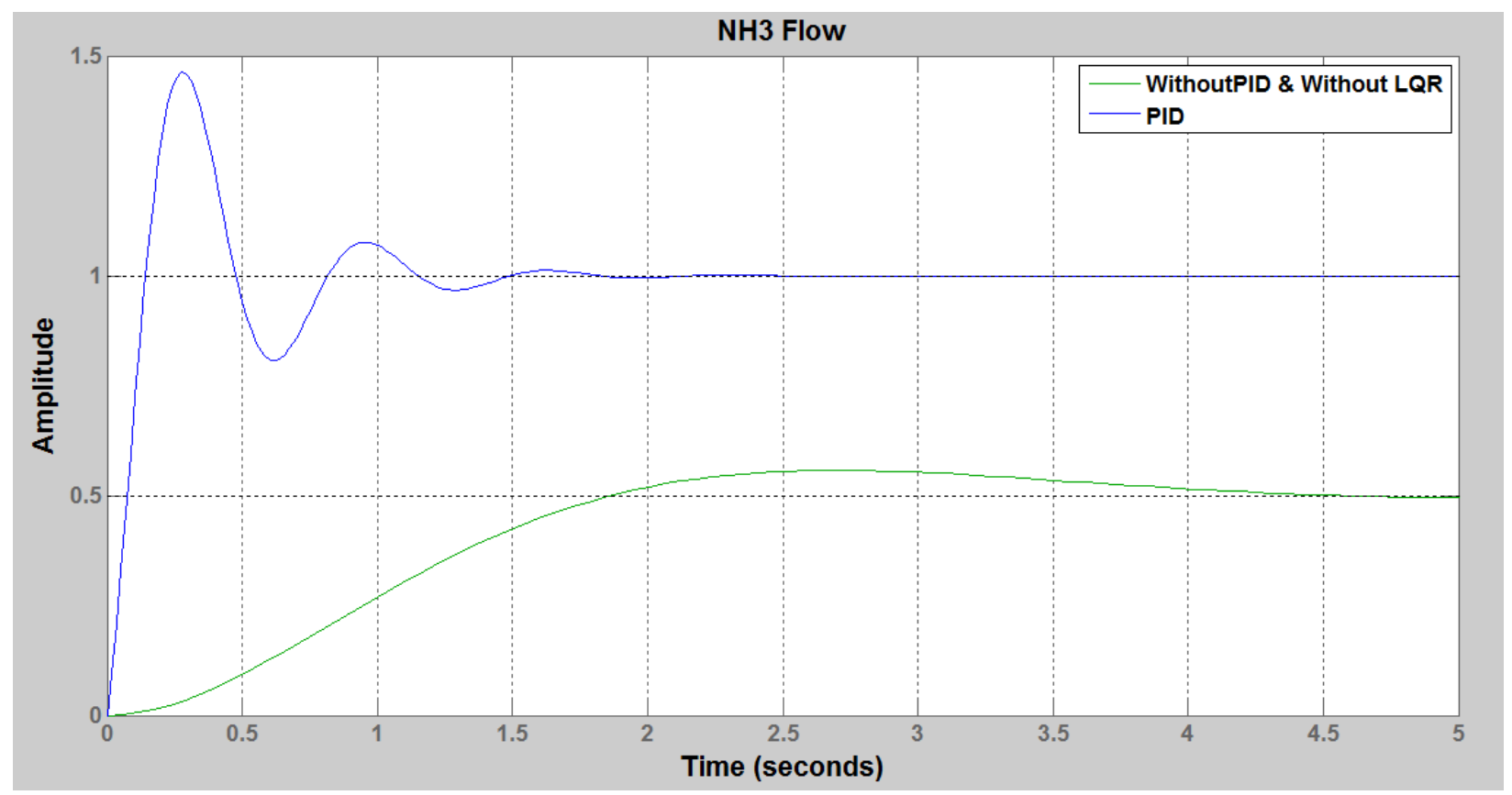

Figure 12: Performance Graph of a NH3 Controller with and without unity Feedback.

\subsection{Generating State Feedback Controller}

To Compute the PID controller cost first step is to find state space equation of the transfer function $\mathrm{G}(\mathrm{s})$. We have to construct a state space model based on the model representing the continuous time state-space model and the general form is given below:

$$
\begin{aligned}
& \dot{\mathrm{X}}(t)=A x(t)+B u(t) \\
& Y(t)=C x(t)+D u(t)
\end{aligned}
$$

Where $\mathrm{A}$ is the state or system matrix

$\mathrm{B}$ is the input matrix

$\mathrm{C}$ is the output matrix

$\mathrm{D}$ is the Feedforward matrix

$\dot{\mathrm{X}}(t)$ is the state vector and $\dot{\mathrm{X}}(t)=\frac{d}{d x} x(t)$ 
$Y(t)$ is the output vector.

By calculating the state space matrices we get
$\mathrm{A} 1=\left[\begin{array}{cc}-3.208 & -1.286 \\ 2 & 0\end{array}\right]$
$\mathrm{B} 1=\left[\begin{array}{l}1 \\ 0\end{array}\right]$
$\mathrm{C} 1=\left[\begin{array}{ll}0 & 1.286\end{array}\right]$
$\mathrm{D} 1=[0]$

Identity matrix, $I=\left[\begin{array}{ll}1 & 0 \\ 0 & 1\end{array}\right]$

\section{Stability of the Function:}

To analyze the system's lyapunov stability

$$
|s I-A|=0
$$

We get, $|S I-A|=\left[\begin{array}{ll}S & 0 \\ 0 & S\end{array}\right]-\left[\begin{array}{cc}-3.208 & -1.286 \\ 2 & 0\end{array}\right]$

$$
\begin{aligned}
& =\left[\begin{array}{cc}
S+3.208 & 1.286 \\
-2 & S
\end{array}\right] \\
& =S(S+3.208)+2.572=s^{2}+3.208 s+2.573
\end{aligned}
$$

$S=-1.604$ and -1.604

The system is stable. 
Define $u=\left[\begin{array}{ll}G 1 & G 2\end{array}\right]=-G X$ then

$$
\begin{aligned}
\mathbf{A c}_{\mathbf{c}}= & \mathrm{A}-\mathrm{BK}=\left[\begin{array}{cc}
-3.208 & -1.286 \\
2 & 0
\end{array}\right]-\left[\begin{array}{l}
1 \\
0
\end{array}\right]\left[\begin{array}{ll}
G 1 & G 2
\end{array}\right] \\
& =\left[\begin{array}{cc}
-3.208-G 1 & -1.286-G 2 \\
2 & 0
\end{array}\right]
\end{aligned}
$$

So then we have that

$$
\begin{gathered}
\operatorname{det}\left(S I-A_{C}\right)=\left[\begin{array}{ll}
S & 0 \\
0 & S
\end{array}\right]-\left[\begin{array}{cc}
-3.208-G 1 & -1.286-G 2 \\
2 & 0
\end{array}\right] \\
=\left[\begin{array}{cc}
S+3.208+G 1 & 1.286+G 2 \\
-2 & S
\end{array}\right] \\
S(S+3.208+G 1)+2(1.286+G 2)=0
\end{gathered}
$$

Compare the desired characteristic equation with the poles obtained -1.604 and -1.604

$$
(s+1.604)(s+1.604)=s^{2}+3.208 s+2.573=0 \text { With above equation }
$$

Thus $G=\left[\begin{array}{ll}0 & 0.4080\end{array}\right]$ where we have to check the system for controllability and observability.

\section{Controllability Test:}

If the system is said to be controllable if $\operatorname{det}(\mathrm{CO}) \neq 0$

$$
\begin{gathered}
C O=\left[\begin{array}{lll}
B & A B & A^{2} B \ldots \ldots A^{n-1} B
\end{array}\right] \\
\left.\mathrm{B}=\left[\begin{array}{l}
1 \\
0
\end{array}\right] \quad \mathrm{AB}=\left[\begin{array}{cc}
-3.208 & -1.286 \\
2 & 0
\end{array}\right]\right] \cdot\left[\begin{array}{l}
1 \\
0
\end{array}\right]=\left[\begin{array}{c}
-3.208 \\
2
\end{array}\right]
\end{gathered}
$$




$$
\begin{gathered}
\mathrm{CO}=\left[\begin{array}{ll}
\mathrm{B} & \mathrm{AB}
\end{array}\right]=\left[\begin{array}{cc}
1 & -3.208 \\
0 & 2
\end{array}\right] \\
\operatorname{det}(\mathrm{CO})=2 \neq 0
\end{gathered}
$$

Thus the system is controllable.

\section{Observability Test:}

The system must be observable to see the happenings inside any system.

If the system is said to be observable if $\operatorname{det}(\mathrm{CO}) \neq 0$

$$
\begin{aligned}
& \mathrm{OB}=\left[\begin{array}{c}
C \\
C A \\
C A \\
\cdot \\
\cdot \\
C A^{n-1}
\end{array}\right] \\
& \mathrm{C}=\left[\begin{array}{ll}
0 & 1.2860
\end{array}\right] \\
& \mathrm{CA}=\left[\begin{array}{lll}
0 & 1.2860
\end{array}\right] \cdot\left[\begin{array}{cc}
-3.208 & -1.286 \\
2 & 0
\end{array}\right]=\left[\begin{array}{ll}
2.572 & 0
\end{array}\right] \\
& \mathrm{OB}=\left[\begin{array}{cc}
0 & 1.2860 \\
2.572 & 0
\end{array}\right] \\
& \operatorname{Det}(\mathrm{OB})=0-3.3075=-3.3075 \neq 0
\end{aligned}
$$

Thus the system is observable.

By finding the controllability and observability we ensure the stability of an unstable system by feedback or an optimal control. 


\subsection{Computation of Nominal Cost function of Ammonia Controller}

A dynamic system described by a differential equation and finding a cost function is essential. Control will allow the system to converge towards the desired state, handled through a feedback input depending upon the state of the system.

We need to minimize

$$
J=\int_{t 0}^{t 1}\left[x^{T} Q x(t)+u^{T}(t) R u(t)\right] d t
$$

Where $\mathrm{Q}$ is a positive semi-definite matrix attributed to state

$\mathrm{R}$ is a positive definite matrix attributed to the input

$\mathrm{t} 1$ and $\mathrm{t} 2$ are initial and final time respectively

We know that $u(t)=-F(t) x(t)$

When $\mathrm{t} 1 \rightarrow \infty$ then $u=-F x(t)$ where $\mathrm{F}$ is the constant feedback gain of the system.

$$
F=-R^{-1} B^{-T} K
$$

$\mathbf{K}$ is nothing but the algebraic Riccati equation.

\section{Nominal Cost function Solution:}

We have got $A_{c}=A-B G$ closed loop system having Algebraic Riccati equation in the form

$$
0=A^{T} P+P A-P S P+Q
$$

Where A, S and Q are symmetric matrices defined by the system. We define the Hamiltonian matrix as $\mathrm{H}$ which is a $2 \times 2$ matrix 


$$
\mathrm{H}=\left[\begin{array}{cc}
A & -S \\
-Q & -A^{\wedge} T
\end{array}\right] \text { and } \mathrm{P}=\left[\begin{array}{ll}
P 1 & P 2 \\
P 2 & P 3
\end{array}\right]
$$

By rewriting Riccati equation,

$$
0=P A_{c}+A_{c}^{T}+Q_{c}
$$

We assume $Q=\left[\begin{array}{ll}1 & 0 \\ 0 & 0\end{array}\right], \mathrm{G}=\left[\begin{array}{ll}0.000 & 0.4080\end{array}\right]$ and $\mathrm{R}=[0.00001]$

Using MATLAB, using lyapunov function we found the value of $Q_{c}=\left[\begin{array}{cc}1.0001 & 0.000 \\ 0.000 & 0.000\end{array}\right]$

After obtaining the value of $Q_{c}$ substitute in the equation to find the value of $P$

$\mathrm{P}=\left[\begin{array}{ll}P 1 & P 2 \\ P 2 & P 3\end{array}\right]=\left[\begin{array}{cc}0.1559 & 0 \\ 0 & 0.2424\end{array}\right]$

The cost function is given by,

$$
J=\frac{1}{2} \cdot X(0) \cdot P \cdot X(0)
$$

Where we have defined $\mathrm{X}(0)$ based on concentration of NOx and Ammonia at the initial state.

$$
\begin{aligned}
X(0)=\left[\begin{array}{c}
30 \\
0
\end{array}\right] \\
J=\frac{1}{2} \cdot\left[\begin{array}{ll}
30 & 0
\end{array}\right] \cdot\left[\begin{array}{cc}
0.1559 & 0 \\
0 & 0.2424
\end{array}\right] \cdot\left[\begin{array}{c}
30 \\
0
\end{array}\right] \\
J=70.1372
\end{aligned}
$$

The nominal cost is 70.1372 


\section{Implementing LQR Technique in NH3 Controller}

The Linear Quadratic Regulator is used in Optimal Control where our main aim is to minimize the cost function. It is the special case of an optimal control problem which is of particular importance arises when the objective function is a quadratic function of $\mathbf{x}$ and $\mathbf{u}$, and the dynamic equations are linear. The resulting feedback law in this case is known as LQR and the performance Index is given by

$$
J=\frac{1}{2} x\left(t_{f}\right)^{T} s_{f} x\left(t_{f}\right)+\frac{1}{2} \int_{t 0}^{t f}\left(x(t)^{T} Q x(t)+\left(u(t)^{T} R u(t)\right) d t\right.
$$

Where $s_{f}$ and $Q$ are the positive definite matrices and the system obey the law

$$
\dot{\mathrm{X}}(t)=A x(t)+B u(t), x\left(t_{0}\right)=x_{0}
$$

Where $\mathrm{A}$ is the system matrix and $\mathrm{B}$ is the input matrix

The Optimal control law can be expressed as a linear state feedback:

$$
u(t)=-K(t) x(t)
$$

And the feedback gain is given by $K(t)=R^{-1} B^{T} s(t)$ and

$S(t)$ is the solution to the Riccati equation

$$
S=A^{T} S+S A-S B R^{-1} B^{T} S+Q \quad \text { and } \quad S\left(t_{f}\right)=s_{f}
$$

In this particular case where $t_{f} \rightarrow \infty$ provided $(A, B)$ is stabilizable, the Riccati equation converges to a limiting solution $S$ and the constant feedback gain is given by $K$ given by

$$
K=R^{-1} B^{T} S
$$

Where $S$ is the positive definite solution of algebraic Riccati equation 


$$
A^{T} S+S A-S B \dot{R}^{-1} B^{T} S+Q=0
$$

If the pair $(A, C)$ is observable where $C^{T} C=Q$, then the closed loop system

$$
\dot{\mathrm{X}}=(\mathrm{A}-\mathrm{BK}) \mathrm{X}
$$

This closed loop system is asymptotically stable provides a way of stabilizing any linear system that is stabilizable.

We find the solution for S (Energy minimization) in order to find the minimum cost of the Linear Quadratic Regulator.

\subsection{Computing Minimum Cost in NH3 Controller}

The LQR problem is defined as follows:

$$
J_{L Q R}=\int_{0}^{\infty}\|z(t)\|^{2}+\rho\|u(t)\|^{2} d t
$$

Where $\rho$ is a positive constant and the term $\int_{0}^{\infty}\|z(t)\|^{2}$

Corresponds to the energy of the controlled output and the term to the energy of the control signal.

$$
\int_{0}^{\infty}\|u(t)\|^{2}
$$

We have to place the poles such that closed-loop system optimizes the cost function

$$
J_{L Q R}=\int_{0}^{\infty}\left[x(t)^{T} Q x(t)+u(t)^{T} R u(t)\right) d t
$$

Where $x^{T} Q x$ is the state cost with weight $Q$.

$u^{T} Q u$ Is the control cost with weight $R$. 
Equation (24) solves the Algebraic Riccati equation where $K$ is the gain, $\mathrm{S}$ is the output of the LQR and $\mathrm{e}$ is a non-singular value. Regardless of the values of $\mathrm{Q}$ and $\mathrm{R}$, the cost function has a unique minimum that can be obtained by solving Algebraic Riccati Equation. The parameters $\mathrm{Q}$ and $\mathrm{R}$ can be used as design parameters to fine tune the state variables and the control signals.

Higher the value of R means you try to stabilize the system with less (weighted) energy called expensive control strategy.

Smaller the value for R means you don't want to penalize the control signal called cheap control strategy.

Ensuring above conditions we have chosen $\mathrm{Q}$ matrix as $\left[\begin{array}{ll}1 & 0 \\ 0 & 0\end{array}\right]$ and $\mathrm{R}=[0.00001]$ Output of LQR, S is $\left[\begin{array}{cc}0.0031 & 0 \\ 0 & 0.0020\end{array}\right]$

Minimum cost $\mathrm{J} *$ is given as

$$
\begin{gathered}
J *=\frac{1}{2} X^{T} S X \\
J *=1.4087
\end{gathered}
$$

By comparing the value of $J$ and $J *$, we can conclude that $J *<J$. Thus, the minimum cost is lesser than nominal cost.

\subsection{Comparison of PID and LQR Performance in Ammonia Controller}

We have recorded the performance of PID and LQR controller and the graph is given below. The LQR output is directly proportional to the amount of ammonia released, which reacts with NOx. 


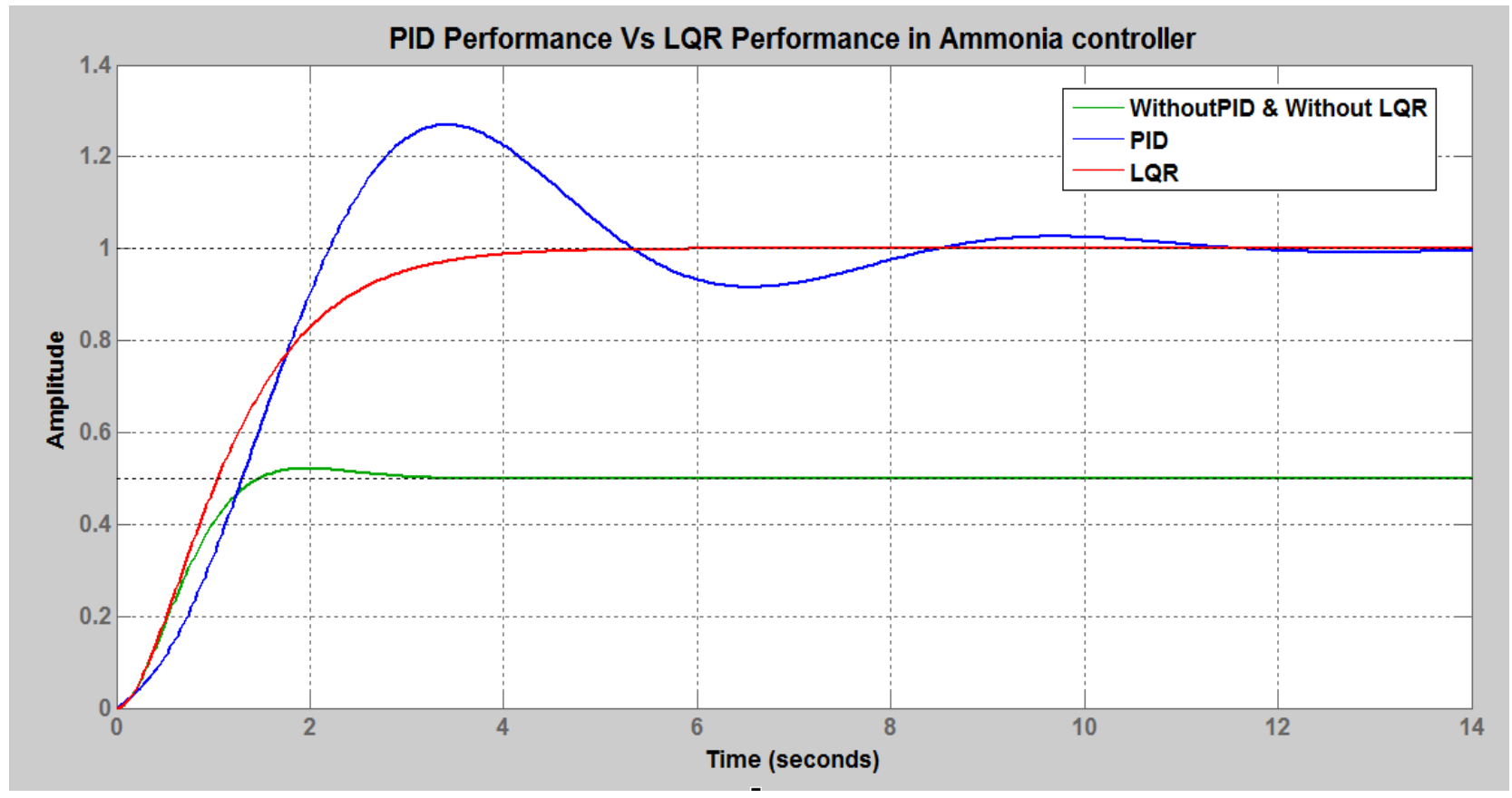

Figure 13: Performance Comparison of NH3 controller implementing PID VS LQR. The settling time of PID controller is 11.8 seconds, whereas the settling time of LQR controller is 4.56 seconds.

Linear Quadratic Regulator has the better performance here due to Low cost, less overshoot, faster settling time and less peak value when compared to PID.

\section{Results and discussion}

From the simulation results, we can conclude that LQR has a better performance than PID Controller. From the graphs below we can infer that LQR has less overshoot, less setting time and less peak value. Comparing the results from cost function we get lesser cost in case of LQR in both NOx and NH3 controller. 


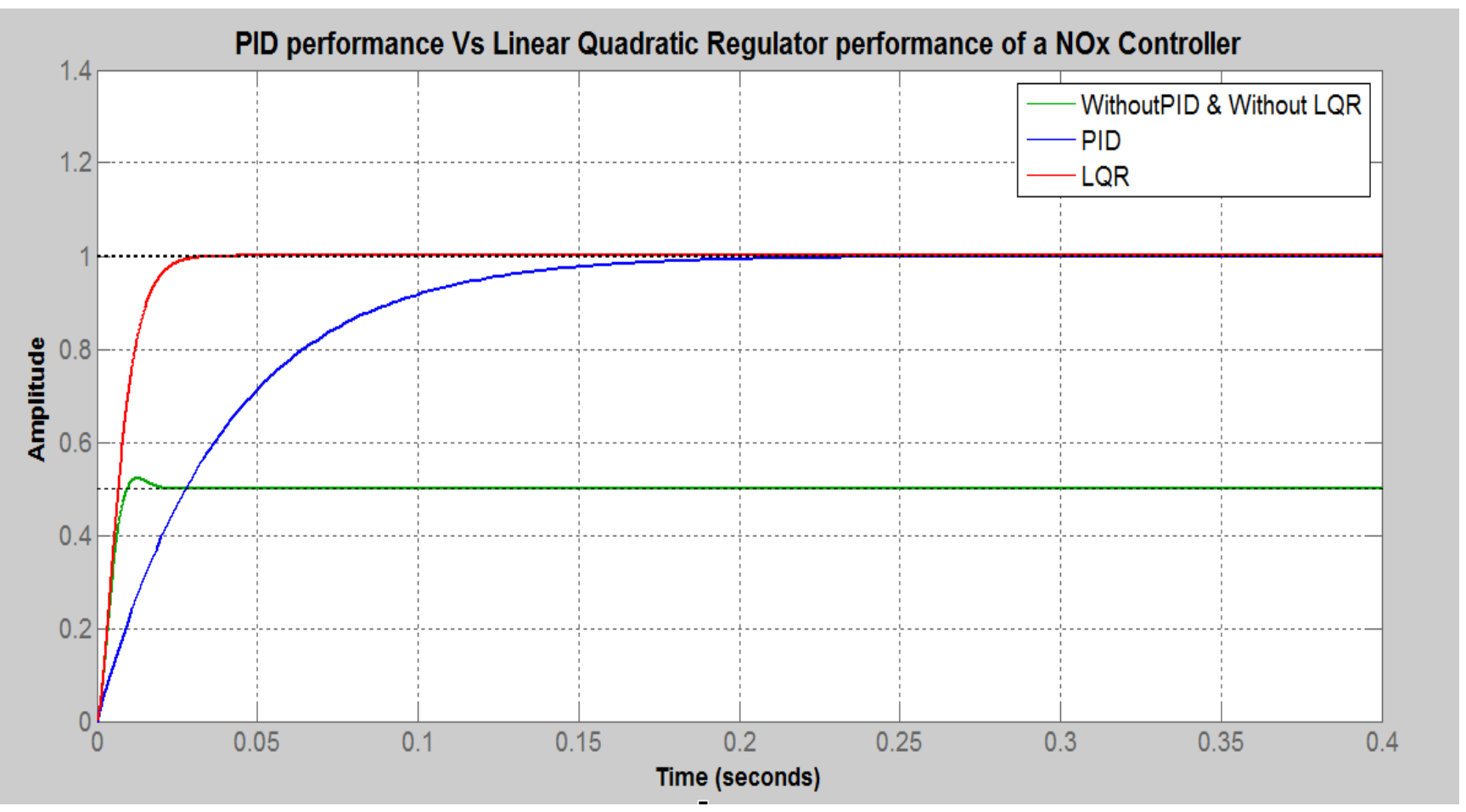

Figure 14: Comparing Results of PID VS LQR Techniques Implemented in NOx Controller

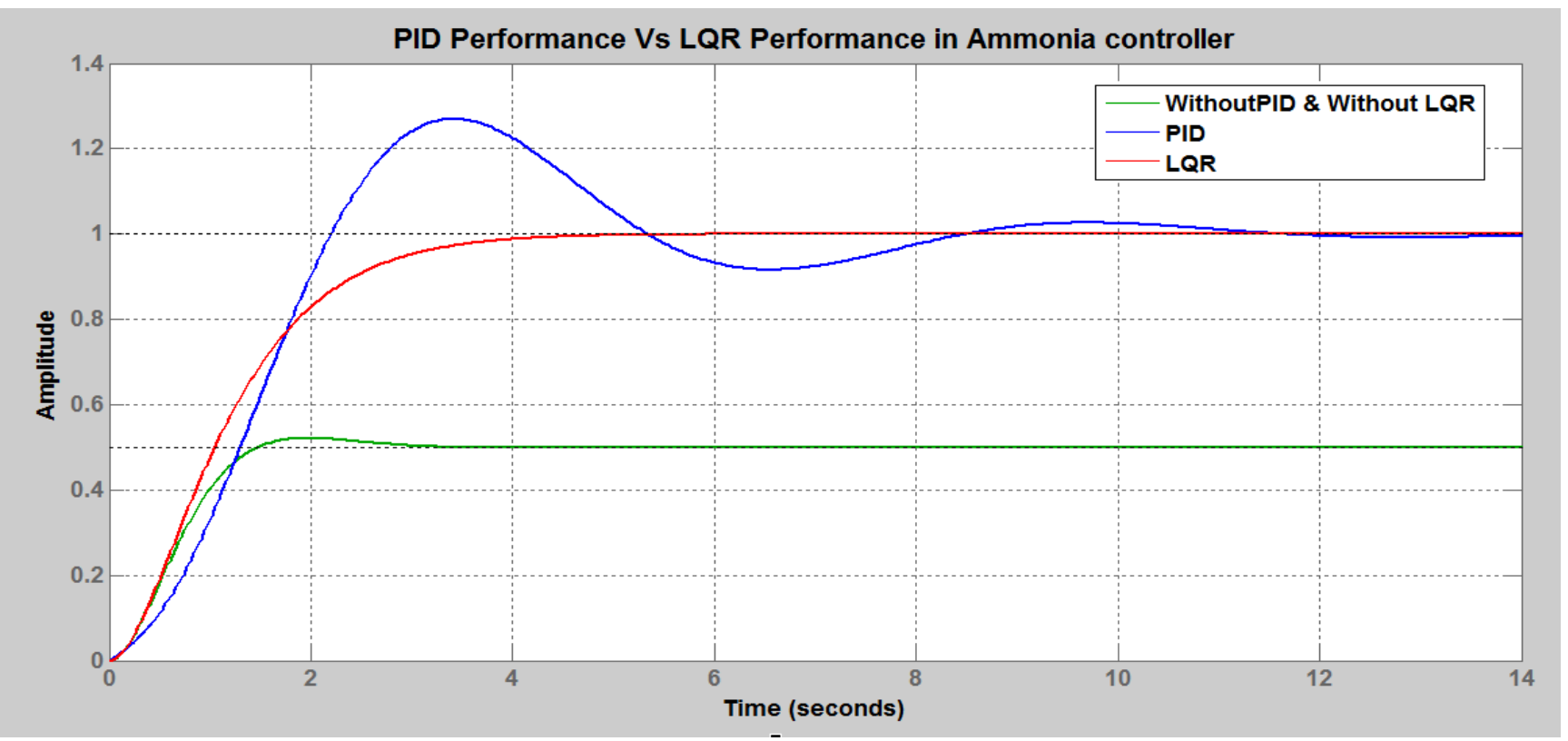

Figure 15: Comparing Results of PID Vs LQR techniques Implemented in NOx Controller 
In NOx controller in figure (14) we can observe that the settling time taken for an LQR is 0.0498 seconds which is lesser than PID settling time which is 0.226 seconds. In Ammonia (NH3) Controller in Figure (15) Settling time taken for a PID controller is 11.8 seconds whereas LQR settling time is 4.56 seconds.

From Chapters 5 and 7, by comparing nominal and minimum costs of both the controllers we infer that LQR technique gives the minimum cost which is lesser than the nominal cost of the system.

In figure (15) we get peak overshoot in Ammonia controller using PID which is overcome by LQR technique.

\section{Conclusion and Future Scope}

In this paper, we have discussed Selective Catalytic Reduction process to reduce NOx concentration. The classical PID controllers have been used in the existing system in SCR process to control the NOx and Ammonia where the PID parameters are calculated based on the plant transfer function. In order to improve the performance and to reduce the energy of the system, we introduced LQR controller in place of PID controller. Linear Quadratic Regulator not only minimizes the energy of the system but also gives the minimized cost which is lesser than the nominal cost. This Technique using Linear Quadratic Regulator has more advantages in terms of both performance and cost when compared to that of a PID controller. This Technique can be applied to existing combustion process in Heaters, boilers, and Furnaces. The capital cost using is $1000-10,000 \$$ per ton whereas the cost using LQR is $500-2000 \$$ ton per hour. We can conclude that optimal control in Selective catalytic Reduction overall improvement in performance and in capital cost. 
But LQR method may still have issues related to noise and time delay. Thus, further improvements can be made in LQR so that it withstand noise and randomness in the system due to uncertainties. Moreover, an extension of the LQR concept to systems with Gaussian additive noise, which is known as the linear quadratic Gaussian (LQG) controller can be used along with existing LQR for further improvements in terms precision, noise, and Randomness which can also be widely applied in Robotics and Automotive applications also. 
REFERENCES 


\section{REFERENCES}

[1] Manashi Nakamoto, Takashi Kokubo, Akinori Kamito "Cascade Control Using GPC and LQR for a NOx Reduction Process of a Thermal Power Plant" Trans. of the Society of Instrument and Control Engineers Vol.E-2, No.1, 98/107(2002)

[2] Nagai, Sagara, Takatsuka, Dehon "Ammonia injection prediction control in the denitration Equipment", Mitsubishi Heavy Industries Technical Review, 25-1, 32/36 (1988)

[3] Pyeongtaek, Akiyama, Oki, Inoue, original "The development of fuzzy theory application control system in the denitration control of the boiler", Japan Society of Mechanical Engineers period 71st National Conference Proceedings, D, 488/490 (1993)

[4] Yokoyama, Kawakami, Ito, Kato: "Denitration NOx control by Fajii control in coal-fired power plant”, electrical critic, 1994-3, 46/51 (1994)

[5] Shimizu, Nakamoto, Kokubo, Tanabe "Generalized predictive control denitration control of a combined cycle power plant" by, Instrument and Control Society Papers, 32-6, 912/920 (1996)

[6] Santo Wijaya, Keiko Shimizu and Masashi Nakamoto "A LQR Scheme for SCR Process in Combined-Cycle Thermal Power Plants", Adconp 2014

[7] H.Peng, T.Osaki, V.Haggan-Ozaki and Y.Toyoda, "A nonlinear Exponential ARX modelbased multivariable generalized predictive control strategy for thermal power plants", IEEE Trans.Control System Technology, Vol.10, no.2, pp.256-262, 2002.

[8] Gregot Dolanc, Stanko Strmenik, Janko Petrovcic, "Model-based control of Selective Catalytic Reduction of Nitric Oxides" Industrial Electronics, 1999. ISIE '99. Proceedings of the IEEE International Symposium (Volume: 3)

[9] Fogman C.B Brummer, T.A “Ammonia storage for NOx Control”, Hydrocarbon Processing, August, 1991.

[10] Ron D.Bell, P.E., MPR Associates, Inc., Fred P. Buckingham "An Overview of Technologies for Reduction of Oxides of Nitrogen from Combustion Furnaces" MPR Associates, Inc, Revision 0, July 2015.

[11] Holland, Dr. Charles D., "A Summary of NOx Reduction Technologies", Texas Institute for Advancement of Chemical Technology, 2002. 
APPENDIXES 


\section{A. MATLAB code for Chapter 4 and 5 in NOx Controller}

clear all;

close all;

$\mathrm{ClC}$;

\% Real time values of the parameters Fuel gas flow rate, Inlet NOx and Outlet

№x values

$\mathrm{FS}=83.000$

InNox=500;

OuNox $=250 * 5$

\% calculation of NOx percentage from Percentage block

NOxDiff=InNox-OuNox;

PerNOx=NOxDiff/InNox;

syms s;

\% To Construct Bode plot for PID-I to ensure stability without unity feedback

$\frac{\circ}{0}[$ num, den $]=\operatorname{ord} 2(250,1)$;

tf1=tf $\left(250^{\wedge} 2,\left[\begin{array}{llll}1 & 2 * 1 * 250 & 250 \wedge 2\end{array}\right]\right) ;$

figure (1)

bode (tf1);

$[\mathrm{magH}, \mathrm{phaseH}]=$ bode $(\mathrm{tf} 1)$;

응 To Construct Bode plot for PID-I with unity Feedback 
$\mathrm{H}=1$;

figure (2)

step (feedback (tf1,H), 'g-'); hold on; owith unity feedback

o Declaring PID Control Parameters based on Real time values

$\mathrm{kp}=0.2$;

$\mathrm{ki}=25$;

$\mathrm{kd}=4 * 10^{\wedge}-4$

CNOx $=p i d(k p, k i, k d) ;$ o Output of PID-I controller

oTNOx=feedback $(\mathrm{CNOx} * t f 1, \mathrm{H})$;

TNOx $=f e e d b a c k\left(\mathrm{CNOx}^{\star} t \mathrm{f} 1, \mathrm{H}\right)$;

figure (2)

step (TNOx, 'b-'); hold on; PID-I controller waveform

\% Define system inputs obtained from state space model of the transfer

ㅇ function

$$
\begin{aligned}
& \mathrm{A} 1=\left[\begin{array}{lll}
-500 & -244.1 ; 256 & 0
\end{array}\right] \\
& \mathrm{B} 1=[16 ; 0] \\
& \mathrm{C} 1=\left[\begin{array}{ll}
0 & 15.26
\end{array}\right] \\
& \mathrm{D} 1=0 \\
& I=\left[\begin{array}{ll}
1 & 0 ;
\end{array}\right. \\
& \left.\begin{array}{ll}
0 & 1
\end{array}\right]
\end{aligned}
$$


응 Check for stability

poles = eig $(A 1)$;

for $i=1$ : length (poles);

if $\operatorname{poles}(i,:)<=0$

disp('System is stable')

break

else

disp('System is unstable')

end

end

응 Check for controllability

$\mathrm{CO} 1=\operatorname{rank}(\operatorname{ctrb}(\mathrm{A} 1, \mathrm{~B} 1))$

if $\mathrm{CO1}==$ length $(\mathrm{A} 1)$

disp('System is controllable')

else

disp('System is uncontrollable')

end

응 Check for observability

$\mathrm{CO} 1=\operatorname{rank}(\mathrm{obsv}(\mathrm{A} 1, \mathrm{C} 1))$

if $\mathrm{CO}==$ length $(\mathrm{A} 1)$

disp ('System is observable')

else

disp ('System is unobservable')

end 
응 응 PART1: GENERATE STATE FEEDBACK CONTROLLER

$\%$

응 Define the desired poles to be placed by the controller $\mathrm{p} 1=\mathrm{pole}(\mathrm{tf} 1)$;

$\circ \mathrm{p} 1=\left[\begin{array}{ll}-250 & -250\end{array}\right]$

$\circ$

\% Find State feedback gains for respective poles

$\mathrm{G} 1=\operatorname{acker}(\mathrm{A} 1, \mathrm{~B} 1, \mathrm{p} 1)$

$\circ$

\% Find feedforward gain for respective poles

$\circ g 1=\left(-1 /\left(C *(A-B u * K 1)^{\wedge}-1 * B u\right)\right)$

$\%$

\% Generate state space model for respective poles

ㅇs $1=s s\left(A-B u^{\star} K 1,\left[B{ }^{\star} g 1 B w\right], C, 0\right)$

$\frac{\circ}{0} t=0: 0.01: 10$;

$\div u=\operatorname{zeros}(1$, length $(t))$;

응 Case1: Declaring $2, R$ and $N$ values to compute Cost function of PID-1 controller

$\mathrm{Q} 1=\left[\begin{array}{llll}1 & 0 ; & 0 & 0\end{array}\right]$

$\mathrm{R} 1=0.00001$

$\mathrm{N} 1=0$

$\mathrm{QC1}=\mathrm{Q} 1+\left(\mathrm{G} 1^{\prime} * \mathrm{R} 1 * \mathrm{G} 1\right)$

$\mathrm{P} 1=1 \mathrm{yap}(\mathrm{A} 1, \mathrm{Qc1})$

$\mathrm{X} 0=[30 ; 0] ;$ 


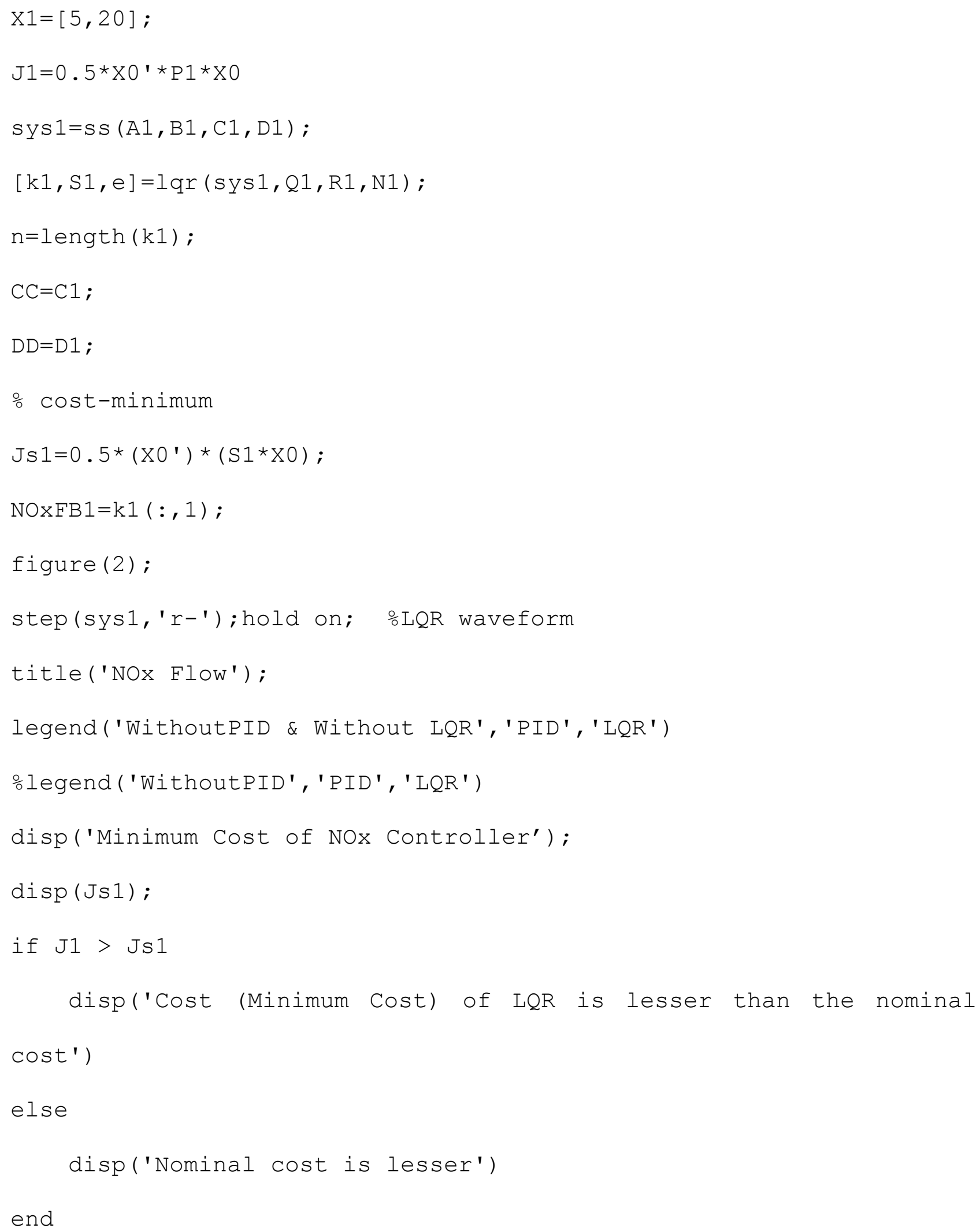




\section{B. MATLAB code for Chapters 6 and 7 in NH3 controller}

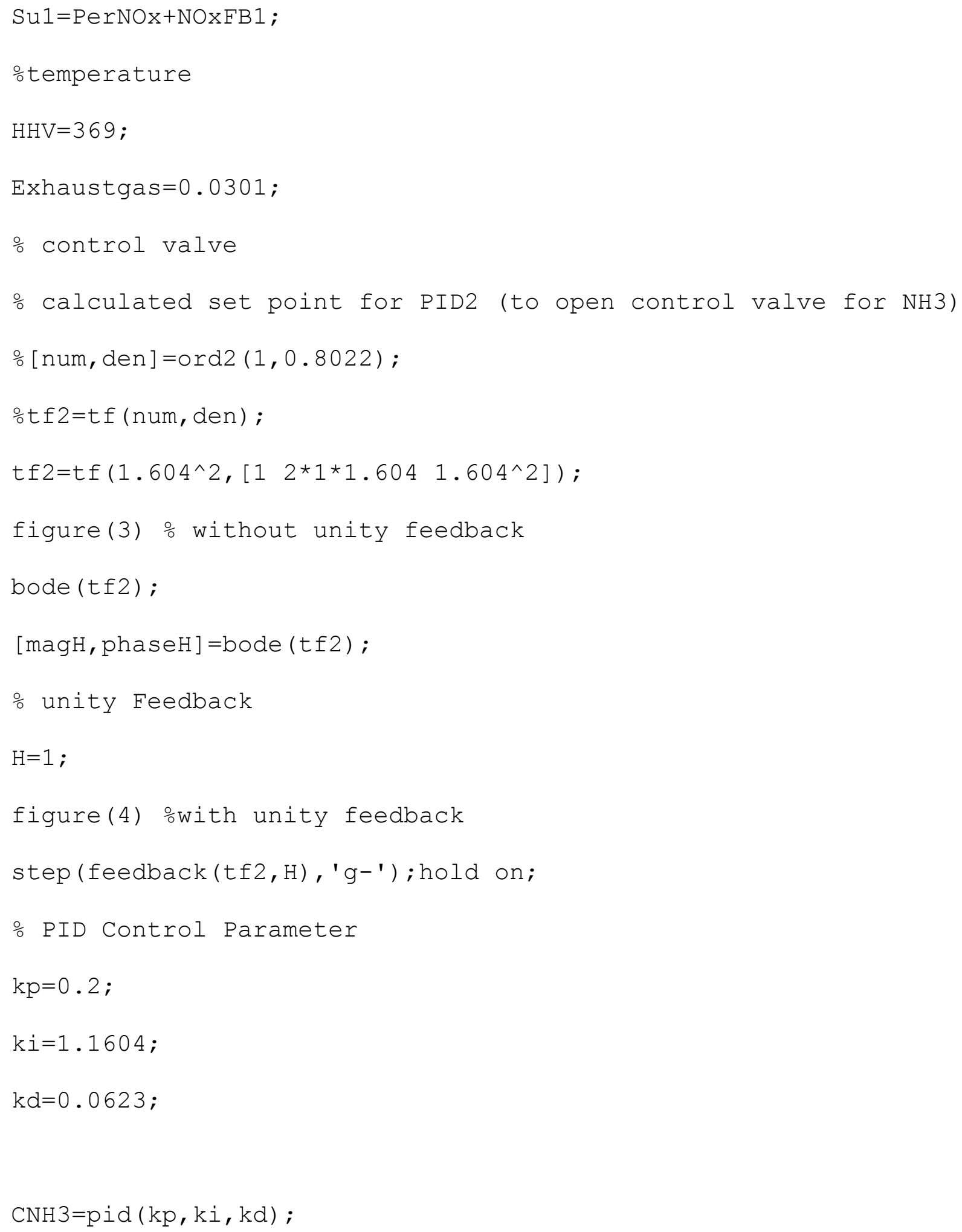




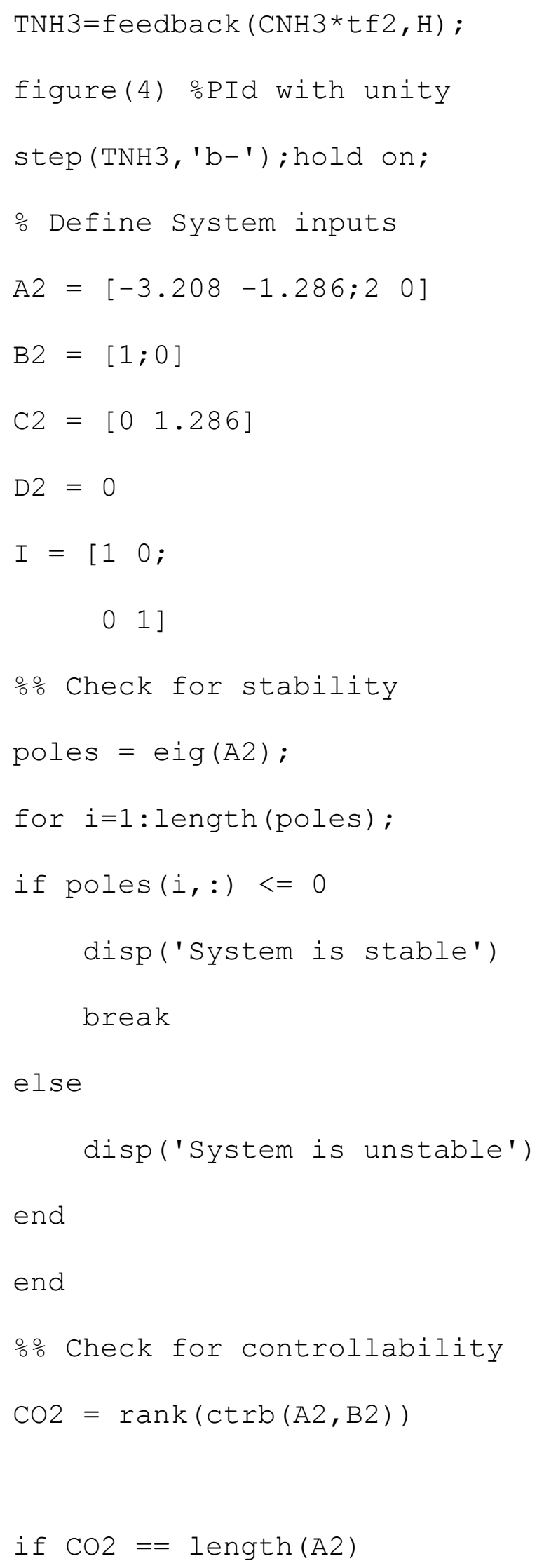




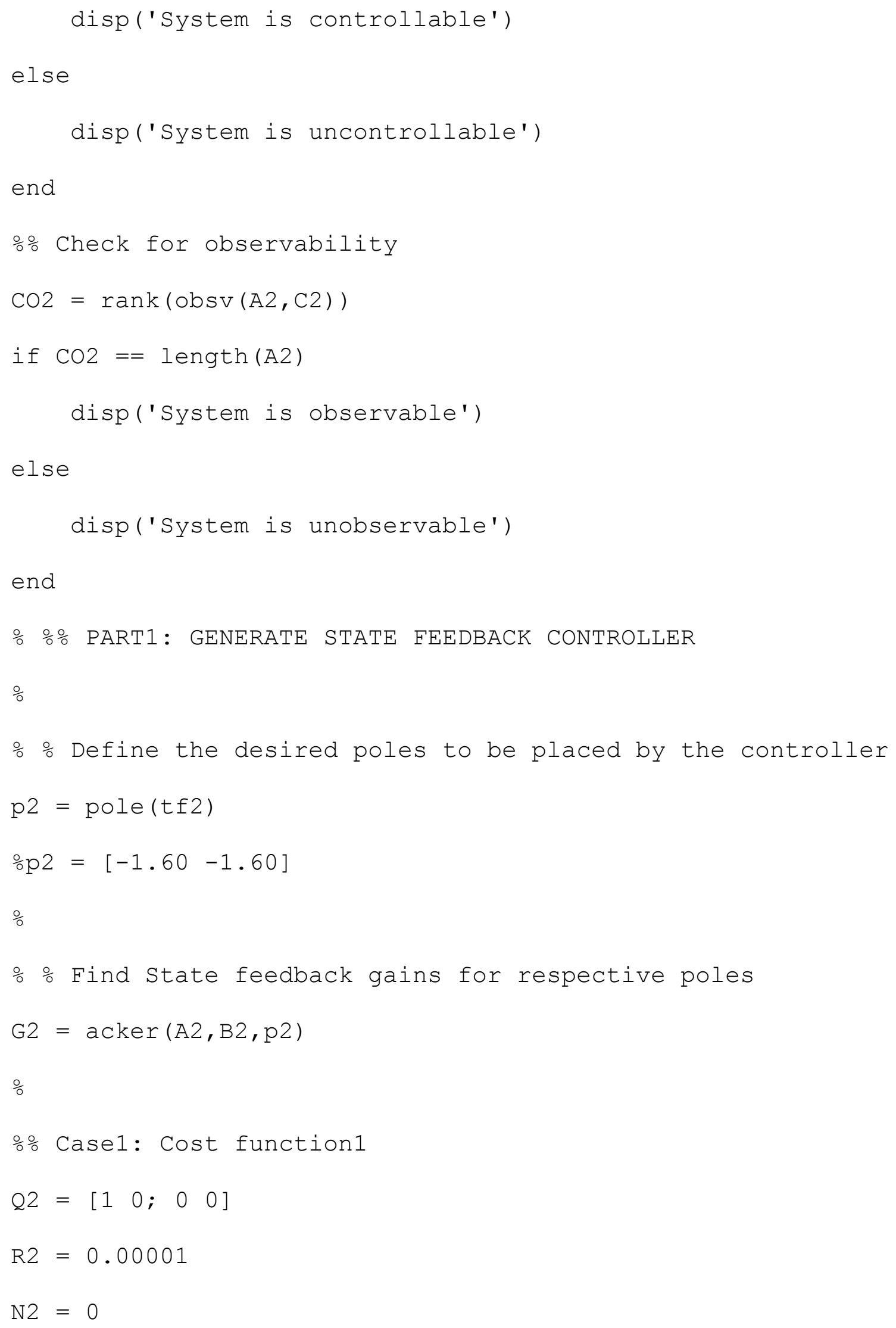


\% Simulate plant state and control input for cost function

\% The Control input is given by,

$\frac{\circ}{o}(t)=-K^{*} x(t)$

$\mathrm{Qc} 2=\mathrm{Q} 2+(\mathrm{G} 2 \cdot * \mathrm{R} 2 * \mathrm{G} 2)$

$\mathrm{P} 2$ = Iyap $(\mathrm{A} 2, \mathrm{Qc} 2)$

$\mathrm{X} 0=[30 ; 0] ;$

$\mathrm{X} 1=[5,20] ;$

$\mathrm{J} 2=0.5 * \mathrm{X}_{0} \cdot * \mathrm{P} 2 * \mathrm{X} 0$

sys $2=s s(A 2, B 2, C 2, D 2) ;$

$[\mathrm{k} 2, \mathrm{~s} 2, \mathrm{e}]=\operatorname{lqr}(\mathrm{sys} 2, \mathrm{Q} 2, \mathrm{R} 2, \mathrm{~N} 2)$;

n=length $(k 2)$;

$\mathrm{CC}=\mathrm{C} 2$;

$\mathrm{DD}=\mathrm{D} 2$

\% cost-minimum

$\mathrm{Js} 2=0.5 *\left(\mathrm{X} 0^{\prime}\right) *(\mathrm{~S} 2 * \mathrm{X} 0) ;$

$\frac{\circ}{\circ}=-\operatorname{inv}(R) *\left(B 1^{\prime}\right) * K$;

$\circ \mathrm{AA}=\mathrm{A} 1-\mathrm{B} 1 * \mathrm{~K} 1 ; \% \mathrm{AC}=\mathrm{A}-\mathrm{BF}$

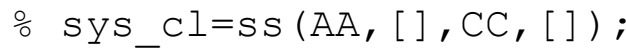

o initial (sys_cl, $[0 ; 0])$;

$\therefore \mathrm{NOXFB2}=\mathrm{S} 2$;

$\mathrm{NH} 3 \mathrm{OP}=\mathrm{k} 2(:, 1)$

figure (4);

step (sys2,'r-'); hold on; $L Q R$ waveform

title('NH3 Flow'); 
legend('WithoutPID \& Without LQR', 'PID', 'LQR')

disp('Minimum Cost of PID2 is');

$\operatorname{disp}(J s 2)$;

if J2 > Js2

disp('Cost (Minimum Cost) of LQR is lesser than the cost of PIDII')

else

disp('Nominal cost is lesser')

end

ocalculating the set point of Ammonia

$\operatorname{ExhFlow}=((\mathrm{FS} * H H V) /(1000000 *$ Exhaustgas $)) ;$

NH3SetPoint $=$ Sul ${ }^{*}$ InNox $*$ ExhFlow;

disp('Setpoint of Ammmonia is calculated as ')

disp (ceil (NH3SetPoint)); 